\title{
Mesenchymal stromal cell therapy for coronavirus disease 2019: which? when? and how much?
}

\author{
Pradnya Shahani, Indrani Datta* \\ Department of Biophysics, National Institute of Mental Health and Neurosciences, Bengaluru, India
}

\section{A R T I C L E I N F O}

\section{Article History:}

Received 9 December 2020

Accepted 10 April 2021

\section{Key Words:}

CD142

hyper-coagulopathy

immunomodulation

SARS-CoV-2

cytokine storm

MSC dosage

\begin{abstract}
A B S T R A C T
Mesenchymal stromal cells (MSCs) are under active consideration as a treatment strategy for controlling the hyper-inflammation and slow disease progression associated with coronavirus disease 2019 (COVID-19). The possible mechanism of protection through their immunoregulatory and paracrine action has been reviewed extensively. However, the importance of process control in achieving consistent cell quality, maximum safety and efficacy-for which the three key questions are which, when and how much-remains unaddressed. Any commonality, if it exists, in ongoing clinical trials has yet to be analyzed and reviewed. In this review, the authors have therefore compiled study design data from ongoing clinical trials to address the key questions of "which" with regard to tissue source, donor profile, isolation technique, culture conditions, long-term culture and cryopreservation of MSCs; "when" with regard to defining the transplantation window by identifying and staging patients based on their pro-inflammatory profile; and "how much" with regard to the number of cells in a single administration, number of doses and route of transplantation. To homogenize MSC therapy for COVID-19 on a global scale and to make it readily available in large numbers, a shared understanding and uniform agreement with respect to these fundamental issues are essential.
\end{abstract}

(c) 2021 International Society for Cell \& Gene Therapy. Published by Elsevier Inc. All rights reserved.

\section{Pathogenesis and Complications of Coronavirus Disease 2019}

The coronavirus disease 2019 (COVID-19) pandemic caused by novel severe acute respiratory syndrome coronavirus 2 (SARS-CoV-2) arose in 2019 and quickly spread around the globe in 2020. The disease presents with a wide range of clinical symptoms, ranging from asymptomatic to mild flu-like symptoms to severe acute respiratory distress syndrome (ARDS), resulting in widespread fatalities from respiratory insufficiency, thrombosis and multi-organ failure. The progression of COVID-19 is further characterized using a three-stage classification system from Siddiqi and Mehra [1] that involves grades of increasing severity defined by distinct clinical symptoms and clinical signs. During stage I, at the time of inoculation and multiplication of SARS-CoV-2, the major symptoms that arise are fever, malaise, dry cough and loss of taste or smell [1,2]. Diagnosis at this stage is through polymerase chain reaction using a nasal or throat swab, serum testing for SARS-CoV-2 IgG and IgM antibodies, chest imaging and tests for complete blood count and liver function. Lymphopenia and neutrophilia are reported during stage I [1]. During stage II, the pulmonary phase of the disease is initiated, featuring mainly shortness of breath. Patients develop pneumonia with cough, fever and

\footnotetext{
* Correspondence: Indrani Datta, PhD. Department of Biophysics, National Institute of Mental Health and Neurosciences, P.B. No 2900, Hosur Road, Bengaluru 560029, India.

E-mail address: indranidatta.nimhans@gmail.com (I. Datta).
}

hypoxia (defined as $\mathrm{PaO}_{2} / \mathrm{FiO}_{2} \leq 300 \mathrm{mmHg}$ ). Lymphopenia and transaminitis are also observed at this stage. Further, computed tomography of the lungs reveals ground-glass opacities at this stage, similar to those seen in conventional ARDS. In both COVID-19 and conventional ARDS, bilateral infiltrates are observed [3]. The symptoms of fever, dry cough and shortness of breath are also similar to symptoms reported in conventional ARDS and acute lung injury (ALI). Finally, stage III of the illness manifests as an extrapulmonary systemic hyper-inflammatory syndrome with symptoms of ARDS, systemic inflammatory response syndrome/shock, vasoplegia and respiratory and cardiac failure. However, this severe stage of the illness is observed in a minority of COVID-19 patients. Similar to secondary hemophagocytic lymphohistiocytosis, systemic multi-organ failure may occur in this advanced stage [4].

Although the mechanisms of pathophysiology remain unclear, the critical role of the immune system in advancing the disease has been well documented [5,6]. Assessment of these immunopathological features has revealed two key events: (i) direct tropism of SARS-CoV-2 toward angiotensin-converting enzyme 2 (ACE2)-positive epithelial cells of the lungs, which results in epithelial cell death and is a "localized" event, and (ii) concurrent increased secretion of interferons (IFNs) by infected cells as an anti-viral defense response that then stimulates secretion of other pro-inflammatory cytokines. Crucially, SARS-CoV-2 appears capable of disrupting these anti-viral inflammatory reactions by blunting type I/III IFN cytokines while increasing other pro-inflammatory cytokines-mainly IL-6 and tumor necrosis 
factor (TNF) $\alpha$ [7]-which results in an acute hyper-inflammatory response known as the cytokine storm, which is a "systemic" event. Wauters et al. [7] have also presented a compelling model cross-linking these two pathologies and culminating in the classic symptoms of COVID-19.

Although the term "cytokine storm" has been used widely over the last year in describing the disease pathophysiology, recent reports have questioned its relevance to the disease. The hyperinflammatory response in COVID-19 has been compared with cytokine release syndrome, a life-threatening toxicity seen in ARDS, chimeric antigen receptor T-cell therapy and sepsis [8,9]. Comparison with previously published data has revealed that although COVID-19 patients present with a higher than normal plasma IL- 6 value, it is 42 , five, 85 and 27 times lower than that seen with hyper-inflammatory ARDS, hypo-inflammatory ARDS, chimeric antigen receptor T-cell therapy and sepsis, respectively [9]. In addition, other pro-inflammatory cytokines (IL- 8 and TNF- $\alpha$ ) appear to be significantly lower in severe COVID-19 compared with these conditions. Following these data, the descriptor "cytokine storm" in COVID-19 may be misleading; however, despite its lower intensity, the occurrence of extrapulmonary systemic inflammation seen in COVID-19 is undeniable. Patients with severe COVID-19 typically present with elevated serum levels of pro-inflammatory cytokines and markers IL-6, TNF- $\alpha$, IL- $1 \beta$ and $\mathrm{C}$-reactive protein (CRP) in addition to other interleukins that drive hyper-inflammation. Additionally, post-mortem analysis of lungs from severe COVID-19 patients has revealed lymphocyte and M1/pro-inflammatory macrophage infiltration that also might cause a hyper-inflammatory response [10].

However, the impact of COVID-19 is not limited to the respiratory system alone. Though it was initially thought to be a severe respiratory disease, several reports of fatalities from multi-organ dysfunction and failure have surfaced [11]. ACE2 is a component of the renin-angiotensin-aldosterone system, which plays a crucial role in controlling blood pressure by maintaining fluid and electrolyte balance in the physiological functioning of various organs and other body tissues, including the heart, vasculature, kidneys, adrenal cortex, basal ganglia and brainstem, where it regulates vasoconstriction $[6,11]$. ACE2 is abundantly expressed on vascular smooth muscle cells, arterial and venous endothelial cells and pericytes, thus facilitating entry of the virus into the vasculature [12]. Once the virus gains entry, ACE2 is unavailable to cleave angiotensin I, thus activating the classical arm of the renin-angiotensin-aldosterone system pathway, resulting in vasoconstriction, fibrosis, oxidative stress and inflammation [6]. Upon infection, endothelial cells undergo apoptosis, disrupt intercellular junctions and lose contact with the basal membrane, resulting in the loss of integrity of the endothelium. By contrast, the uncontrolled hyper-inflammation causes endothelial cell activation and a pro-thrombotic phenotype. Platelet aggregation, vasoconstriction and increased reactive oxygen species generation eventually impair vascular tone [12-14]. Consequently, thrombocytopenia, reduced anticoagulants and blood clots lead to the disseminated intravascular coagulopathy (DIC) that is observed in patients with severe COVID-19 [15,16]. A key aspect that differs from conventional ARDS and sepsis is the profound coagulopathy that COVID-19 patients suffer from [16]. The ACE2 receptor is extensively expressed in various organs (heart, kidneys, lungs and intestines), which explains fatalities resulting from blood clots and multi-organ failure. Patients with underlying comorbidities of diabetes and hypertension and those with immunocompromised conditions are more likely to experience severe COVID-19 symptoms [17-19]. Furthermore, a growing number of cases of encephalopathy and ischemic and hemorrhagic stroke are being reported with COVID-19 and have resulted in higher morbidity and mortality [20,21]. Elevated levels of CRP, fibrinogen and D-dimer in patients with severe COVID-19 are clinically relevant biomarkers and are indicative of a pro-thrombotic state and a high probability of developing DIC. Assessment of serum
D-dimer levels has proven beneficial in rapidly identifying patients who are at risk of developing DIC or pulmonary thromboembolism and require intensive care [22-25].

\section{Mesenchymal Stromal Cells to Target Hyper-Inflammation in COVID-19}

The failure of anti-viral drugs has prompted the reorientation of treatment strategies toward reversing the cytokine storm and rebuilding the host immune system. To achieve this, immunomodulatory drugs (e.g., corticosteroids, chloroquine and hydroxychloroquine) and anti-IL-6 antibodies or cytokine blockers (e.g., tocilizumab) have been proposed [26-28]. However, as cytokines are pleiotropic, blocking them could hamper the balance of a regulated immune response, resulting in autoimmune effects, tissue damage and a compromised host immune system. Further, cytokine functions have mutual redundancy: the function of a blocked cytokine can be compensated by another [29]. In a recent study, clinical improvement and mortality were statistically comparable between tocilizumab and standard treatment patients in the cohort. Also, the same study found that bacterial or fungal infections were recorded in 13\% of tocilizumab patients and $12 \%$ of standard treatment patients, suggesting that the IL- 6 blocker alone was insufficient for controlling the dysregulated immune cascade [30].

Use of adult mesenchymal stromal cells (MSCs) may be a more effective approach for achieving immunosuppression and immunomodulation. The mechanisms by which MSCs achieve this through their paracrine action or by direct cell-cell contact with immune cells (Figure 1) have been well established. In summary, MSCs suppress the proliferation and activation of cytotoxic $\mathrm{T}$ cells via the release of TGF- $\beta$ and hepatocyte growth factor (HGF), resulting in decreased cyclin D2 and increased p27kip1 expression in T cells, thus arresting proliferation in the G1 phase [31-33]. Moreover, MSCs induce apoptosis of activated T cells via the Fas/Fas ligand-dependent pathway, suppress IFN- $\gamma$ and IL-17 secretion and promote IL-10 production by inducing the generation of regulatory T cells [34,35]. However, these effects can be achieved only when MSCs are prestimulated by certain inflammatory cytokines (IFN- $\gamma$ and TNF- $\alpha$, IL$1 \alpha$ or IL- $1 \beta$ ). Therefore, transplantation into an inflammatory milieu may actually help in "activating" or "licensing" their immunosuppressive response [36-38]. In response to stimulation by these inflammatory cytokines, MSCs upregulate their inducible nitric oxide synthase and cyclooxygenase 2 expression levels, resulting in robust production of nitric oxide and prostaglandin E2 (PGE2) [39]. Interaction of the inhibitory molecule programmed death 1 (PD1) with its ligands PD-L1 and PD-L2 has also been demonstrated in the inhibition of T-cell proliferation by MSCs via direct cell-cell contact [40]. In addition, MSCs inhibit differentiation of monocytes into dendritic cells (DCs) and thus DC maturation, giving rise to immature DCs that render T cells anergic, in addition to inducing upregulation of anti-inflammatory cytokine IL-10 and downregulation of pro-inflammatory cytokines IFN- $\gamma$, IL-12 and TNF- $\alpha$, inducing a more anti-inflammatory DC phenotype [41,42]. MSCs also suppress proliferation of natural killer cells and decrease the secretion of IFN- $\gamma$ by IL-2-stimulated natural killer cells. A combination of effects involving cell-cell contact and paracrine factors, including TGF- $\beta 1$, PGE2 and indoleamine-2,3dioxygenase (IDO), is reported to be responsible for this observation [43]. MSCs also suppress M1 type macrophages (pro-inflammatory) and induce M2 type macrophages (anti-inflammatory) in a process that is mediated by secreted PGE2 [44,45].

In addition to the aforementioned immunosuppressive mechanisms, MSCs bring about regeneration of damaged tissue by the secretion of a plethora of growth factors. Previous studies in ARDS have demonstrated the role of MSCs in lung regeneration through the production of keratinocyte growth factor, vascular endothelial growth factor (VEGF) and 


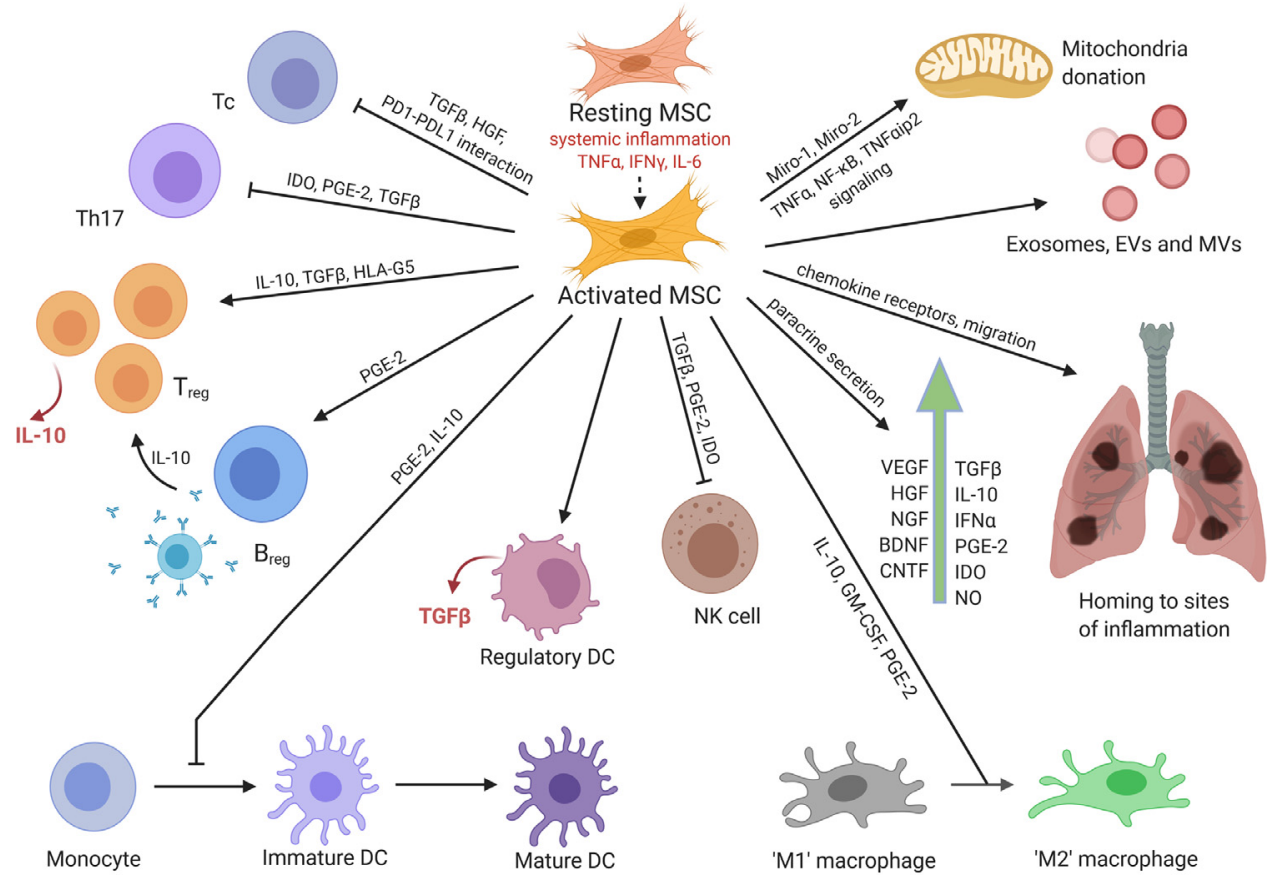

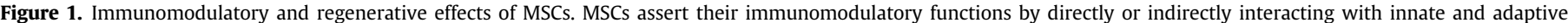

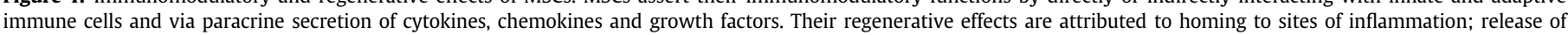

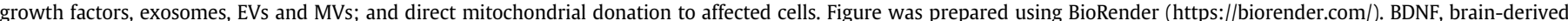

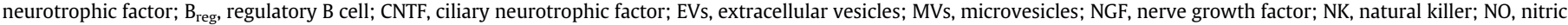
oxide. (Color version of figure is available online).

HGF [46-48]. MSCs have also been shown to promote the regeneration of ATII cells and contribute to repair of the alveolar-epithelial barrier of ARDS-injured lungs [49]. Additionally, the promotion of alveolar fluid clearance by MSCs has been shown to depend upon claudin 4, which belongs to a family of proteins centrally involved in tight junction formation. A clinical study conducted by Chen et al. [50] investigated the safety and efficacy of menstrual blood-derived MSCs in improving lung function in moderate to severe influenza A (H7N9)-induced ARDS. No adverse effects were observed and multiple doses of MSCs were well tolerated. Improvement was observed in CRP, creatine kinase, prothrombin and D-dimer, indicating the efficacy of MSCs in treating the condition [51].

Furthermore, MSCs are proven to bring about endothelial cell repair. MSCs secrete VEGF, which brings about differentiation of endothelial progenitor cells into endothelial cells [52]. An in vitro study demonstrated that adipose-derived MSC (AD-MSC) exosomes transfer miR-125a to primary human umbilical vein endothelial cells, enhancing tube formation and increasing tube length and number of branches and therefore promoting angiogenesis [53]. Another in vitro study showed that an MSC-endothelial cell co-culture significantly reduced endothelial paracellular and transcellular permeability via secretion of HGF in an ALI model induced by lipopolysaccharides. The effects were achieved by remodeling intercellular junctions and increasing proliferation of human pulmonary microvascular endothelial cells [54]. Furthermore, in a clinical study conducted by Premer et al., 2015 [55] in which patients with idiopathic dilated and ischemic cardiomyopathy were transplanted with autologous or allogeneic MSCs, the allogeneic MSC treatment resulted in improved endothelial function 3 months post-transplantation. Based on these preliminary data, MSCs appear to be a strong candidate for treating COVID-19.

\section{MSC Therapy for ARDS and ALI: Lessons from the Past}

Over the past decade, MSCs have been extensively studied in vitro, in vivo and in clinical trials as treatment for conventional ARDS and ALI [3,56,57] and have been deemed safe for transplant in conventional ARDS. However, ARDS is merely one of the conditions seen in COVID-19-one that is to some extent a driver of the pathophysiological state. COVID-19 also appears to be a microvascular or "blood disease" that presents with unusual hematological effects. Brault et al. [58] compared parameters between moderate and severe ARDS related to COVID-19 and ARDS resulting from other factors (mostly pneumonia and influenza) and observed that dissociation between respiratory mechanics and gas exchange was comparable between the two groups. About $60 \%$ of the COVID-19 cases presented with predominant ground-glass opacities with alveolar consolidation [58]. Similar findings in COVID-19 ARDS cases were also reported by Haudebourg et al. [59]. Furthermore, the intensity of the systemic inflammation in COVID-19 versus conventional ARDS was minimal. Despite these similarities with conventional ARDS, COVID-19 is not limited to the respiratory system alone. As discussed earlier, a hypercoagulable state is also prevalent, as evidenced by elevated D-dimer, thrombin and factor V and VIII levels. In addition, the increased production of pro-inflammatory cytokines triggers the release of procoagulant mediators and results in platelet aggregation [60].

Several clinical trials have reported the safety of MSC administration in patients with severe ARDS, with very few or no infusionrelated adverse effects. Of note is the prospective, double-blind, multi-center, randomized START study in which $10 \times 10^{6}$ bone marrow-derived MSCs (BM-MSCs) per kilogram of body weight were transplanted intravenously into 40 ARDS patients. A significant decrease in Ang-2 levels was observed and attributed to reduced inflammation [61]. In addition, the randomized, placebo-controlled, phase 2a MultiStem study evaluated the safety and efficacy of adult BM-MSCs and reported that MSC treatment was associated with a higher score for number of ventilator-free days, better quality of life outcomes and, more importantly, reduced levels of IL-6, IL- $1 \beta$ and IFN- $\gamma 7$ days post-transplantation [57].

Although these clinical trials demonstrated the safety of MSC therapy in conventional ARDS, the safety of intravenous infusions in COVID-19 remains a challenge owing to the predominant pro-coagulable state. As MSCs express tissue factor (TF) or CD142 [16], there is 
a possibility of exaggerated coagulopathy upon intravenous administration of MSCs during stage III, or the hyper-inflammatory phase [1], of COVID-19. To avoid this, and to achieve a favorable risk-benefit ratio, a transplantation window needs to be identified based on a disease staging system, keeping in mind the simultaneous pulmonary and extrapulmonary manifestations.

\section{Current Scenario of MSC Use for COVID-19}

A pilot study conducted by Leng et al. [62] at Beijing YouAn Hospital, Capital Medical University, Beijing, China, tested the safety and efficacy of intravenous transplantation of ACE2-negative MSCs (the MSC tissue source was not specified) and showed promising results. Seven patients (one critically ill, four severely ill and two moderately ill) received a single dose of $1 \times 10^{6}$ cells $/ \mathrm{kg}$ body weight with or without conventional anti-pyretic/anti-viral treatment and underwent a follow-up period of 14 days. All patients recovered or were discharged within 4-6 days of intervention. The improvement was attributed to a decrease in CRP, normalized platelet count, increased levels of regulatory $\mathrm{CD} 4^{+} \mathrm{T}$ cells and $\mathrm{CD} 14^{+} \mathrm{CD} 11 \mathrm{c}^{+} \mathrm{CD} 11 \mathrm{~b}^{\text {mid }}$ regulatory DCs, decrease in pro-inflammatory cytokines, increase in IL-10, VEGF and IP-10 and decrease in TNF- $\alpha$. No adverse effects in response to MSC transplantation were reported. Furthermore, the gene expression profile of MSCs showed that they were ACE2-negative and transmembrane serine protease 2-negative, suggesting that they could protect themselves from viral attack. Another case report of a severely ill COVID-19 patient was presented by Liang et al. [63] in which three doses of $5 \times 10^{7}$ allogeneic umbilical cord-derived MSCs (UC-MSCs) administered intravenously with thymosin $1 \alpha$ at an interval of 3 days were well tolerated. Serum bilirubin and CRP levels normalized, with an increase in $\mathrm{CD}^{+}, \mathrm{CD}^{+}$and $\mathrm{CD}^{+}$up to normal levels. The researchers also suggested that the effects were largely due to the immunomodulatory action of UC-MSCs and not thymosin $1 \alpha$.

These two preliminary studies led to a snowballing of clinical trials adopting allogeneic adult MSCs or their exosomes as an intervention in controlling the progression of COVID-19 (Table 1). As of November 17, 2020, 60 clinical trials investigating the safety and efficacy of adult allogeneic or autologous MSCs for the treatment or prevention of COVID-19 have been registered at www.clinicaltrials.gov, with umbilical cord/Wharton's jelly being the predominant source of cells (38.33\%), followed by adipose tissue (16.67\%) and bone marrow (16.67\%) (Figure 2A). Other stromal cell sources, such as dental pulp (3.33\%), placenta (3.33\%), umbilical cord blood (1.66\%), umbilical cord lining $(1.66 \%)$ and olfactory mucosa $(1.66 \%)$, are also being investigated. Although 58 of the 60 trials are investigating the safety and efficacy of MSCs in treating COVID-19, two trials are evaluating the prophylactic efficacy of MSCs in health care workers and persons in high-risk jobs (NCT04348435 and NCT04349631, respectively) (Table 1), with one of these two studies (NCT04349631) utilizing autologous AD-MSCs. Only one study out of 60 has chosen the intramuscular route of injection, whereas all others have adopted the intravenous route. A substantial variation is seen in the dosage of MSCs used, ranging from a low of 10 million cells to a high of 400 million cells per dose. There are also differences in the number of injections used and their frequency.

To homogenize MSC therapy for COVID-19 on a global scale and to make it readily available in large numbers, a uniform understanding with respect to fundamental issues, such as ideal tissue source, ideal time of transplantation of MSCs, route of administration and dosage quantity required, is essential. Although a substantial amount of data will indeed be obtained from the results of these clinical trials, making head-to-head comparisons between them will be quite difficult owing to variability in inclusion criteria, tissue source, isolation and culture conditions and, crucially, dosage. As MSCs are biological entities and not chemical drugs, communication between stem cell biologists and clinicians is imperative in taking this approach from bench to bedside. As stem cell biologists, the authors seek to address the practical issues that are faced, from selecting donors to transplanting the cells into patients, so as to make MSC therapy available quickly for COVID-19 on a global scale.

The International Society for Cell \& Gene Therapy has defined minimal criteria for characterizing MSCs that include the following: (i) plastic adherence in standard culture conditions; (ii) positive (95\%) for CD105, CD73 and CD90; (iii) negative for CD45, CD34, CD14 or CD11b, CD79 $\alpha$ or CD19 and HLA-DR; and (iv) in vitro differentiation to osteoblasts, adipocytes and chondrocytes [64]. With these basic characterization guidelines in place, standard operating procedures for isolation, expansion, culture and freezing need to be developed to standardize the process of obtaining "clinical-grade" cells, minimizing differences between manufacturers and batch-to-batch variability.

\section{MSC Tissue Source and Quality: The "Which"}

Adult MSCs can be isolated from several tissue sources, including bone marrow (gold standard), umbilical cord or Wharton's jelly, adipose tissue, dental pulp, peripheral blood, umbilical cord blood and menstrual blood. Of the currently registered clinical trials, umbilical cord (or Wharton's jelly) is the most common source of MSCs and adipose tissue is the second most common (Table 1). Although several reports [65-67] have established the immunomodulatory and regenerative properties of UC/Wharton's jelly (WJ)- and AD-MSCs to be on par or better than BM-MSCs (gold standard), the authors also emphasize their easy availability, ease of isolation, scalability (i.e., obtaining a high number of cells from comparatively little tissue) and possibility of banking. Unfortunately, none of the current clinical studies specify the passage number of the cells at the time of transplantation. An earlier passage would be a crucial factor in efficacy owing to the appearance of cell senescence in later passages [68]. Some factors relating to the manufacturing process that contribute to MSC quality and efficacy are discussed in the following sections.

\section{Tissue Source}

The first issue is selecting an optimal source of tissue from which the highest number of cells of reproducible quality can be obtained at a reasonable cost. Therefore, discarded tissues like umbilical cord and dental pulp, which are easily accessible, cheaply procured and trigger the fewest ethical concerns, are better choices. However, as the quantity of dental pulp isolated from one tooth is far less than the tissue derived from one umbilical cord, several teeth may be required to isolate the same number of cells. Furthermore, although bone marrow can yield only $0.001-0.01 \%$ mononuclear cells, adipose tissue can yield $5 \times 10^{3}$ MSCs per gram, and the yield from Wharton's jelly has been reported to be the highest, at $1-5 \times 10^{4}$ cells $/ \mathrm{cm}$ umbilical cord [69]. Also, WJ-MSCs have a faster proliferation capacity owing to their shorter population doubling time compared with other sources (Table 2), making them an optimal tissue source. Regardless of the choice of tissue source, donor testing for HIV-1, HIV-2, hepatitis C virus, hepatitis B virus, syphilis, human T-cell leukemia virus type 1, human T-cell leukemia virus type 2 and cytomegalovirus remains mandatory.

MSCs isolated from bone marrow, adipose tissue or perinatal tissues are reported to express TF or CD142. Endothelial cell injury can activate the coagulation cascade via TF/CD142 [22]. In a physiological setting, the role of $\mathrm{TF}$ is to initiate extrinsic blood coagulation to arrest bleeding from vascular beds in case of injury. TF overexpression is related to hyper-coagulopathy and is observed in diabetes, cardiovascular disease and other inflammatory conditions [70]. However, TF expression in clinical MSC products positively correlates to the degree of hemo-incompatibility and triggers the instant blood- 
Table 1

List of ongoing clinical trials using MSCs for COVID-19, with a focus on inclusion criteria, tissue source of MSCs, route of administration and dosage.

\begin{tabular}{|c|c|c|c|c|c|c|c|c|}
\hline & $\begin{array}{l}\text { ClinicalTrials.gov } \\
\text { identifier }\end{array}$ & Inclusion criteria & Intervention & $\begin{array}{l}\text { Route of } \\
\text { administration }\end{array}$ & Dosage & $\begin{array}{l}\text { No. of } \\
\text { injections }\end{array}$ & $\begin{array}{l}\text { Interval between } \\
\text { injections, } \mathrm{h}\end{array}$ & $\begin{array}{l}\text { No. of cells/dose } 62-\mathrm{kg} \\
\text { person, million }\end{array}$ \\
\hline 1 & NCT04313322 & Confirmed COVID-19 & Allogeneic WJ-MSCs & Intravenous & $1 \times 10^{6}$ cells $/ \mathrm{kg}$ body weight & 3 & 96 & 62 \\
\hline 2 & NCT04336254 & $\begin{array}{l}\text { COVID-19 with severe } \\
\text { pneumonia }\end{array}$ & Allogeneic DP-MSCs & Intravenous & $30 \times 10^{6}$ cells & 3 & 96 & 30 \\
\hline 3 & NCT04315987 & $\begin{array}{l}\text { COVID-19-positive patients } \\
\text { with pulmonary } \\
\text { impairment } \geq 50 \%\end{array}$ & $\begin{array}{l}\text { NestCell (source not } \\
\text { specified) }\end{array}$ & Intravenous & $20 \times 10^{6}$ cells & 3 & 48 & 20 \\
\hline 4 & NCT04366323 & $\begin{array}{l}\text { COVID-19 with severe or } \\
\text { critical pneumonia }\end{array}$ & Allogeneic AD-MSCs & Intravenous & $80 \times 10^{6}$ cells & 2 & Not specified & 80 \\
\hline 5 & NCT04252118 & $\begin{array}{l}\text { Confirmed COVID-19 with } \\
\text { pneumonia }\end{array}$ & $\begin{array}{l}\text { Allogeneic MSCs (source not } \\
\text { specified) }\end{array}$ & Intravenous & $30 \times 10^{6}$ cells & 3 & 72 & 30 \\
\hline 6 & NCT04273646 & $\begin{array}{l}\text { Confirmed COVID-19 with } \\
\text { pneumonia }\end{array}$ & Allogeneic UC-MSCs & Intravenous & $\begin{array}{l}0.5 \times 10^{6} \text { cells } / \mathrm{kg} \text { body } \\
\text { weight }\end{array}$ & 4 & 48 & 31 \\
\hline 7 & NCT04288102 & $\begin{array}{l}\text { Confirmed COVID-19 with } \\
\text { pneumonia }\end{array}$ & $\begin{array}{l}\text { Allogeneic MSCs (source not } \\
\text { specified) }\end{array}$ & Intravenous & $40 \times 10^{6}$ cells & 3 & 72 & 40 \\
\hline 8 & NCT04346368 & Severe case of COVID-19 & Allogeneic BM-MSCs & Intravenous & $1 \times 10^{6}$ cells $/ \mathrm{kg}$ body weight & 1 & NA & 62 \\
\hline 9 & NCT04382547 & $\begin{array}{l}\text { Confirmed COVID-19 with } \\
\text { pneumonia }\end{array}$ & $\begin{array}{l}\text { Allogeneic Pooled Olfactory } \\
\text { Mucosa-derived MSCs }\end{array}$ & Intravenous & Not specified & Not specified & Not specified & Not specified \\
\hline 10 & NCT04302519 & $\begin{array}{l}\text { Confirmed COVID-19 with } \\
\text { severe pneumonia }\end{array}$ & Allogeneic DP-MSCs & Intravenous & $1 \times 10^{6}$ cells $/ \mathrm{kg}$ body weight & 3 & 48,72 & 62 \\
\hline 11 & NCT04366063 & $\begin{array}{l}\text { Confirmed COVID-19 with } \\
\text { ARDS and pneumonia }\end{array}$ & $\begin{array}{l}\text { Allogeneic MSCs (source not } \\
\text { specified) }\end{array}$ & Intravenous & $100 \times 10^{6}$ cells & 2 & 48 & 100 \\
\hline 12 & NCT04339660 & $\begin{array}{l}\text { Confirmed COVID-19 with } \\
\text { pneumonia }\end{array}$ & Allogeneic UC-MSCs & Intravenous & $1 \times 10^{6}$ cells $/ \mathrm{kg}$ body weight & 1 & NA & 62 \\
\hline 13 & NCT04371601 & $\begin{array}{l}\text { Confirmed COVID-19 with } \\
\text { severe pneumonia }\end{array}$ & Allogeneic UC-MSCs & Intravenous & $1 \times 10^{6}$ cells $/ \mathrm{kg}$ body weight & 4 & 24 & 62 \\
\hline 14 & NCT04355728 & COVID-19 with Severe ARDS & Allogeneic UC-MSCs & Intravenous & $100 \times 10^{6}$ cells & 2 & 48 & 100 \\
\hline 15 & NCT04362189 & Suspected COVID-19 & Allogeneic AD-MSCs & Intravenous & $100 \times 10^{6}$ cells & 4 & 72 & 100 \\
\hline 16 & $\begin{array}{l}\text { NCT04293692 } \\
\text { (withdrawn) }\end{array}$ & $\begin{array}{l}\text { Confirmed COVID-19 with } \\
\text { pneumonia }\end{array}$ & Allogeneic UC-MSCs & Intravenous & $\begin{array}{l}0.5 \times 10^{6} \text { cells } / \mathrm{kg} \text { body } \\
\text { weight }\end{array}$ & 4 & 48 & 31 \\
\hline 17 & NCT04348461 & $\begin{array}{l}\text { Confirmed COVID-19 with } \\
\text { ARDS }\end{array}$ & Allogeneic AD-MSCs & Intravenous & $1 \times 10^{6}$ cells $/ \mathrm{kg}$ body weight & 2 & 0 & 62 \\
\hline 18 & NCT04341610 & $\begin{array}{l}\text { Confirmed COVID-19 with } \\
\text { ARDS and pneumonia }\end{array}$ & Allogeneic AD-MSCs & Intravenous & $100 \times 10^{6}$ cells & 1 & NA & 100 \\
\hline 19 & NCT04371393 & $\begin{array}{l}\text { Confirmed COVID- } 19 \text { with } \\
\text { moderate to severe ARDS }\end{array}$ & $\begin{array}{l}\text { Allogeneic MSCs (source not } \\
\text { specified) }\end{array}$ & Intravenous & $2 \times 10^{6}$ cells $/ \mathrm{kg}$ body weight & 2 & 96 & 124 \\
\hline 20 & NCT04345601 & $\begin{array}{l}\text { Confirmed COVID-19 with } \\
\text { mild ARDS }\end{array}$ & Allogeneic BM-MSCs & Intravenous & $100 \times 10^{6}$ cells & 1 & NA & 100 \\
\hline 21 & NCT04269525 & $\begin{array}{l}\text { Confirmed COVID-19 with } \\
\text { severe pneumonia }\end{array}$ & Allogeneic UC-MSCs & Intravenous & $99 \times 10^{6}$ cells & 4 & 48 & 99 \\
\hline 22 & NCT04361942 & $\begin{array}{l}\text { Confirmed COVID-19 with } \\
\text { pneumonia }\end{array}$ & $\begin{array}{l}\text { Allogeneic MSCs (source not } \\
\text { specified) }\end{array}$ & Intravenous & $1 \times 10^{6}$ cells $/ \mathrm{kg}$ body weight & 1 & NA & 62 \\
\hline 23 & NCT04333368 & $\begin{array}{l}\text { Confirmed COVID-19 with } \\
\text { ARDS }\end{array}$ & Allogeneic UC-MSCs & Intravenous & $1 \times 10^{6}$ cells $/ \mathrm{kg}$ body weight & 3 & 48 & 62 \\
\hline 24 & NCT04389450 & $\begin{array}{l}\text { Confirmed COVID-19 with } \\
\text { ARDS }\end{array}$ & $\begin{array}{l}\text { PLX-PAD (allogeneic pla- } \\
\text { centa-derived MSCS) }\end{array}$ & Intramuscular & Not specified & 2 & 168 & Not specified \\
\hline 25 & NCT04367077 & $\begin{array}{l}\text { Confirmed COVID-19 with } \\
\text { moderate to severe ARDS }\end{array}$ & MultiStem (bone marrow) & Intravenous & Not specified & Not specified & Not specified & Not specified \\
\hline 26 & NCT04366830 & $\begin{array}{l}\text { Confirmed COVID-19 with } \\
\text { moderate to severe ARDS }\end{array}$ & $\begin{array}{l}\text { Remestemcel-L (source not } \\
\text { specified) }\end{array}$ & Intravenous & $2 \times 10^{6}$ cells $/ \mathrm{kg}$ body weight & 2 & Not specified & 124 \\
\hline 27 & NCT04366271 & $\begin{array}{l}\text { Severe lung involvement } \\
\text { associated with SARS- } \\
\text { CoV-2 virus infection }\end{array}$ & Allogeneic UC-MSCs & Not specified & Not specified & Not specified & Not specified & Not specified \\
\hline 28 & NCT04399889 & $\begin{array}{l}\text { Confirmed COVID-19 with } \\
\text { ARDS }\end{array}$ & Allogeneic UC-MSCs & Intravenous & $\begin{array}{l}1 \times 10^{6} \text { cells/kg body weight } \\
\text { (maximum dose } 100 \text { mil- } \\
\text { lion cells) }\end{array}$ & 3 & $18-30$ & 62 \\
\hline
\end{tabular}




\begin{tabular}{|c|c|c|c|c|c|c|c|c|}
\hline & $\begin{array}{l}\text { ClinicalTrials.gov } \\
\text { identifier }\end{array}$ & Inclusion criteria & Intervention & $\begin{array}{l}\text { Route of } \\
\text { administration }\end{array}$ & Dosage & $\begin{array}{l}\text { No. of } \\
\text { injections }\end{array}$ & $\begin{array}{l}\text { Interval between } \\
\text { injections, h }\end{array}$ & $\begin{array}{l}\text { No. of cells/dose/62-kg } \\
\text { person, million }\end{array}$ \\
\hline 29 & NCT04348435 (Prevention) & High-risk job & Allogeneic AD-MSCs & Intravenous & $\begin{array}{l}50 \times 10^{6} \text { cells, } 100 \times 10^{6} \\
\text { cells or } 200 \times 10^{6} \text { cells }\end{array}$ & 5 & 336,672 & 50,100 or 200 \\
\hline 30 & NCT04400032 & $\begin{array}{l}\text { Confirmed COVID-19 with } \\
\text { ARDS }\end{array}$ & Allogeneic BM-MSCs & Intravenous & $\begin{array}{l}25 \times 10^{6} \text { cells, } 50 \times 10^{6} \text { cells } \\
\text { or } 90 \times 10^{6} \text { cells }\end{array}$ & 3 & 24 & 25,50 or 90 \\
\hline 31 & NCT04352803 & $\begin{array}{l}\text { Confirmed COVID-19 but not } \\
\text { severe pneumonia }\end{array}$ & Allogeneic AD-MSCs & Intravenous & $\begin{array}{l}0.5 \times 10^{6} \text { cells } / \mathrm{kg} \text { body } \\
\text { weight }\end{array}$ & 1 & NA & 31 \\
\hline 32 & NCT04349631 (Prevention) & $\begin{array}{l}\text { Health care workers or high- } \\
\text { risk workers with under- } \\
\text { lying health conditions }\end{array}$ & Autologous AD-MSCs & Intravenous & Not specified & 5 & Not specified & Not specified \\
\hline 33 & NCT04377334 & Confirmed COVID-19 & Allogeneic BM-MSCs & Intravenous & Not specified & Not specified & Not specified & Not specified \\
\hline 34 & NCT04390152 & $\begin{array}{l}\text { Confirmed COVID-19 with } \\
\text { moderate to severe ARDS }\end{array}$ & Allogeneic WJ-MSCs & Intravenous & $50 \times 10^{6}$ cells & 2 & Not specified & 50 \\
\hline 35 & NCT03042143 & $\begin{array}{l}\text { Confirmed COVID-19 with } \\
\text { ARDS }\end{array}$ & Allogeneic UC-MSCs & Intravenous & $400 \times 10^{6}$ cells & 1 & NA & 400 \\
\hline 36 & NCT04444271 & $\begin{array}{l}\text { Confirmed COVID-19 with } \\
\text { moderate to critical } \\
\text { pneumonia }\end{array}$ & Allogeneic BM-MSCs & Intravenous & $2 \times 10^{6}$ cells $/ \mathrm{kg}$ body weight & 2 & 144 & 124 \\
\hline 37 & NCT04429763 & Confirmed severe COVID-19 & Allogeneic UC-MSCs & Intravenous & $1 \times 10^{6}$ cells $/ \mathrm{kg}$ body weight & 1 & NA & 62 \\
\hline 38 & NCT04565665 & $\begin{array}{l}\text { Confirmed COVID-19 with } \\
\text { moderate to severe ARDS }\end{array}$ & Allogeneic UCB-MSCs & Intravenous & Not specified & Not specified & Not specified & Not specified \\
\hline 39 & NCT04611256 & $\begin{array}{l}\text { Confirmed COVID-19 with } \\
\text { ARDS }\end{array}$ & Allogeneic AD-MSCs & Intravenous & $1 \times 10^{6}$ cells $/ \mathrm{kg}$ body weight & 2 & 48 & 62 \\
\hline 40 & NCT04456361 & $\begin{array}{l}\text { Confirmed COVID-19 with } \\
\text { ARDS }\end{array}$ & Allogeneic WJ-MSCs & Intravenous & $100 \times 10^{6}$ cells & 1 & NA & 100 \\
\hline 41 & NCT04625738 & $\begin{array}{l}\text { Confirmed COVID-19 with } \\
\text { moderate to severe ARDS }\end{array}$ & Allogeneic WJ-MSCs & Intravenous & $\begin{array}{l}1 \times 10^{6} \text { cells } / \mathrm{kg} \text { body weight } \\
\text { or } 0.5 \times 10^{6} \text { cells } / \mathrm{kg} \text { body } \\
\text { weight }\end{array}$ & 3 & 72 & 62 or 31 \\
\hline 42 & NCT04629105 & $\begin{array}{l}\text { ARDS and acutely infected } \\
\text { with SARS-CoV-2 }\end{array}$ & $\begin{array}{l}\text { Longeveron MSCs (source } \\
\text { not specified) }\end{array}$ & Intravenous & $100 \times 10^{6}$ cells & 3 & Not specified & 100 \\
\hline 43 & NCT04527224 & $\begin{array}{l}\text { Confirmed COVID-19 with } \\
\text { pneumonia }\end{array}$ & $\begin{array}{l}\text { AstroStem-V (allogeneic AD- } \\
\text { MSCs) }\end{array}$ & Not specified & Not specified & Not specified & Not specified & Not specified \\
\hline 44 & NCT04428801 & $\begin{array}{l}\text { Healthy persons highly sus- } \\
\text { ceptible to SARS-Cov-2 } \\
\text { infections }\end{array}$ & Allogeneic AD-MSCs & Intravenous & $200 \times 10^{6}$ cells & 3 & 48 & 200 \\
\hline 45 & NCT04573270 & $\begin{array}{l}\text { COVID-19 patients or health } \\
\text { care providers }\end{array}$ & $\begin{array}{l}\text { PrimePro (allogeneic UC- } \\
\text { MSCs) }\end{array}$ & Intravenous & Not specified & Not specified & Not specified & Not specified \\
\hline 46 & NCT04490486 & $\begin{array}{l}\text { Confirmed COVID-19 with } \\
\text { moderate to severe ARDS }\end{array}$ & Allogeneic UC-MSCs & Intravenous & $100 \times 10^{6}$ cells & 2 & 72 & 100 \\
\hline 47 & NCT04457609 & $\begin{array}{l}\text { Confirmed COVID-19 with } \\
\text { pneumonia }\end{array}$ & Allogeneic UC-MSCs & Intravenous & $1 \times 10^{6}$ cells $/ \mathrm{kg}$ body weight & 1 & NA & 62 \\
\hline 48 & NCT04461925 & $\begin{array}{l}\text { Confirmed COVID-19 with } \\
\text { severe pneumonia }\end{array}$ & $\begin{array}{l}\text { Allogeneic placenta derived- } \\
\text { MSCs }\end{array}$ & Intravenous & $1 \times 10^{6}$ cells $/ \mathrm{kg}$ body weight & 3 & 72 & 62 \\
\hline 49 & NCT04535856 & Mild or moderate COVID-19 & $\begin{array}{l}\text { Dae Woong (DW)-MSCs } \\
\text { (Phamaceutical Co. Ltd.) }\end{array}$ & Intravenous & $\begin{array}{l}50 \times 10^{6} \text { cells or } 100 \times 10^{6} \\
\quad \text { cells }\end{array}$ & 1 & NA & 50 or 100 \\
\hline 50 & NCT04452097 & $\begin{array}{l}\text { Confirmed COVID-19 with } \\
\text { moderate to severe } \\
\text { pneumonia }\end{array}$ & Allogeneic UC-MSCs & Intravenous & $\begin{array}{l}0.5 \times 10^{6} \text { cells } / \mathrm{kg} \text { body } \\
\text { weight, } 1.0 \times 10^{6} \text { cells } / \mathrm{kg} \\
\text { body weight or } 1.5 \times 10^{6} \\
\text { cells } / \mathrm{kg} \text { body weight }\end{array}$ & 1 & NA & 31,62 or 93 \\
\hline 51 & NCT04397796 & $\begin{array}{l}\text { Confirmed COVID-19 with } \\
\text { moderate to severe ARDS }\end{array}$ & Allogeneic BM-MSCs & Intravenous & Not specified & Not specified & Not specified & Not specified \\
\hline 52 & NCT04494386 & $\begin{array}{l}\text { Confirmed COVID- } 19 \text { with } \\
\text { ARDS }\end{array}$ & $\begin{array}{l}\text { Allogeneic umbilical cord } \\
\text { lining stem cells }\end{array}$ & Intravenous & $100 \times 10^{6}$ cells & 2 & 48 & 100 \\
\hline 53 & NCT04390139 & $\begin{array}{l}\text { Confirmed COVID-19 with } \\
\text { moderate ARDS }\end{array}$ & Allogeneic WJ-MSCs & Intravenous & $1 \times 10^{6}$ cells/kg body weight & 2 & 48 & 62 \\
\hline
\end{tabular}




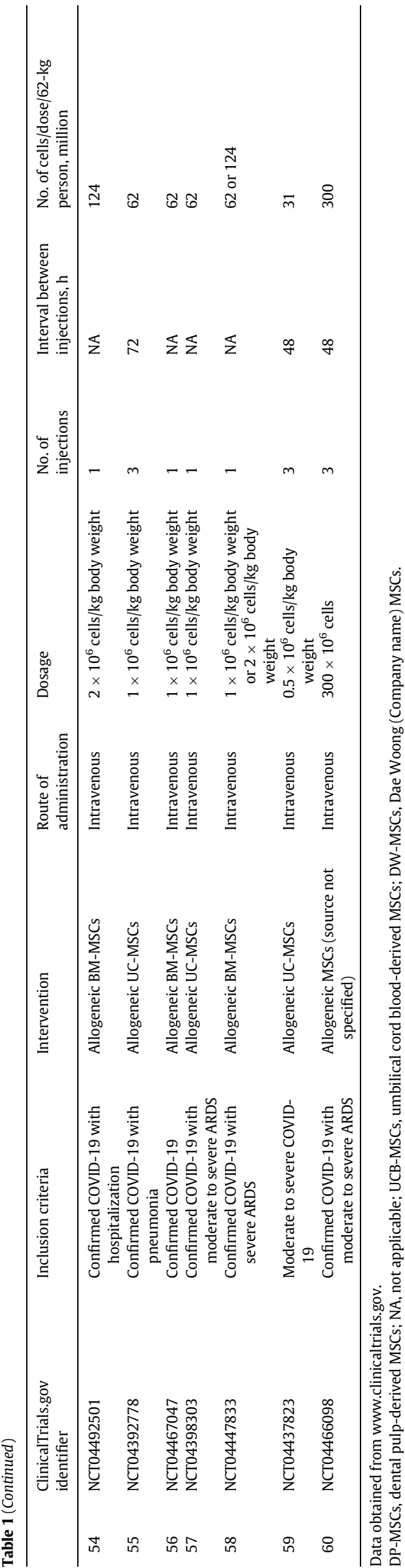

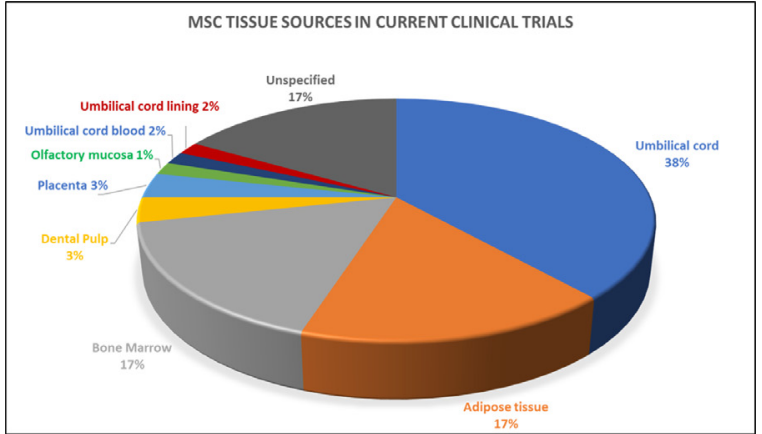

(a)

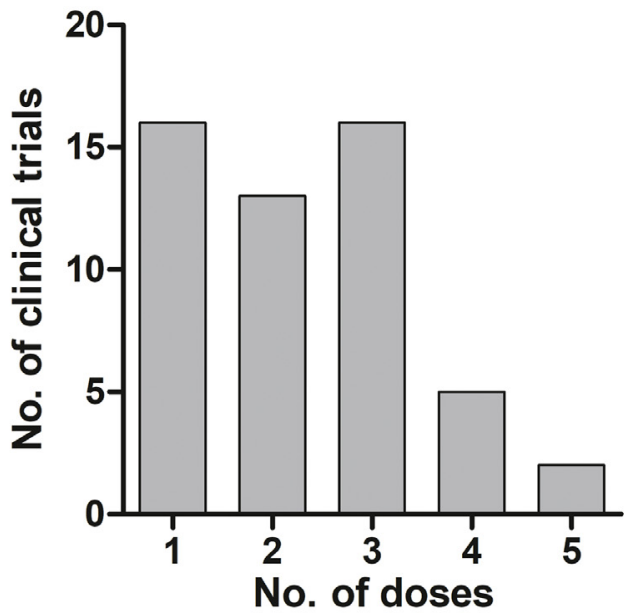

(b)

Figure 2. (A) Various tissue sources of MSCs in current COVID-19 clinical trials. MSCs from umbilical cord, adipose tissue and bone marrow appear to be the predominant MSC tissue sources. (B) Number of MSC doses employed in current COVID-19 clinical trials. One and three doses of MSC infusions are most commonly employed in ongoing trials. Five doses is the highest number of doses observed. Figure data taken from https://clinicaltrials.gov/. (Color version of figure is available online).

mediated inflammatory reaction (IBMIR) [71-73]. AD-MSCs and MSCs derived from perinatal tissues have been reported to have higher TF expression and substantial clotting (i.e., lesser hemocompatibility) compared with BM-MSCs [72]. However, TF expression varies between donors and passage numbers and can become enhanced in an inflammatory micro-environment [71-73]. Since patients with severe COVID-19 and underlying comorbidities like diabetes or hypertension appear to be predisposed to hyper-coagulopathy, screening for TF/CD142 expression via flow cytometry in addition to the existing panel of $\mathrm{CD}$ markers is a key criterion in choosing the optimal source in this scenario.

It should also be noted that MSCs isolated from Wharton's jelly are not the same as MSCs isolated from umbilical cord blood. Wharton's jelly is a gelatinous matrix within the umbilical cord; sometimes the terms "UC-MSCs" and "WJ-MSCs" are used synonymously.

\section{Donor Profile}

Once the optimal source of tissue is identified, the next issue to be addressed is the definition of inclusion/exclusion criteria for MSC donors. Several reports have established that donor age is a crucial factor affecting MSC functions. Siegel et al. [74] reported that BMMSCs isolated from young female donors were higher in number, had higher proliferation and were more immunosuppressive compared with older counterparts [74]. Also, age-related decline in adipogenic, 
Table 2

Comparison of ease of isolation, quantity of tissue and population doubling time of MSCs from different tissue sources.

\begin{tabular}{ll}
\hline MSC source & Ease of isolation \\
\hline Bone marrow & Requires surgical aspiration; painful procedure; smaller quantity of tissue obtained \\
$\begin{array}{l}\text { Adipose tissue } \\
\text { Wharton's jelly (umbilical cord) }\end{array}$ & $\begin{array}{l}\text { Requires liposuction surgery; high quantity of tissue can be obtained } \\
\text { Discarded tissue; easily obtainable in high numbers; high number of cells can be isolated from small quantity } \\
\text { of tissue }\end{array}$ \\
$\begin{array}{ll}\text { Discarded tissue; quality of cells obtained varies drastically between donors owing to tooth decay; } \\
\text { comparatively lowest quantity of tissue }\end{array}$
\end{tabular}

Data taken from [112,113].

osteogenic and neurogenic differentiation potential has been observed in BM-MSCs [75]. In addition, diseases like diabetes, obesity and autoimmune disorders are known to influence the stem cell niche and affect endogenous MSC functions [76-79]. These factors limit the pool and require the identification of "perfect control" donors, which could be rare owing to lifestyle choices. WJ-MSCs, being perinatal in origin, retain the highest telomere length and are protected from years of lifestyleinduced disease conditions and exposure to anti-inflammatory drugs like non-steroidal anti-inflammatory drugs [69], again making umbilical cord an ideal tissue source.

\section{Isolation Technique}

Extensive research has been conducted on the effects of different isolation protocols-from explant cultures to the use of various enzymatic digestion techniques-on yield, phenotype, proliferation and functional aspects of MSCs. Because of the blood-like texture of bone marrow, MSC isolation is performed by plating the buffy coat (containing MSCs, red blood cells and other immune cells) on a tissue culture dish and eventually eliminating non-adherent cells (red blood cells and immune cells). Only the plastic-adherent MSCs remain behind. However, both explant and enzymatic digestion can be used for tissues like adipose tissue, Wharton's jelly and dental pulp. Yoon et al. [79] reported that explant cultures of Wharton's jelly yielded 2.8 times more cells per gram of tissue and had higher proliferation rates and basic fibroblast growth factor secretion compared with enzymatic digestion [80]. Further, longer incubation in enzymes results in loss of cell viability and lower cell yields, requires a greater number of reagents and consumes more media and time. As a very large number of cells are required for transplant into one patient (approximately $30-100 \times 10^{6}$ cells/dose), explant cultures would be cost-effective and efficient with respect to cell quality and time consumed in a Good Manufacturing Practice facility.

\section{Culture Conditions}

A major drawback of studies deploying human MSCs in clinical, pre-clinical and in vitrosettings, irrespective of the disease condition, is the variability in culture conditions. Even slight changes in the percentage of fetal bovine serum (FBS) used in culture media have been shown to affect BM-MSC proliferation and immunosuppressive properties [81]. As FBS is an ill-defined medium component, variations exist between countries of origin, manufacturers and even production lots $[82,83]$. These hamper proliferation and growth factor and cytokine secretion and may even induce immunogenicity [84]. In addition to variability, concerns about xenogenic contaminants such as viruses, bacterial endotoxins, prions and unknown zoonotic pathogens have led to the adoption of serum/xeno-free alternatives [84,85], including StemPro MSC SFM XenoFree (Invitrogen), MesenCult XF medium (Stem Cell Technologies), stemgro human MSC medium (Corning), PowerStem MSC1 (PAN-Biotech) and TheraPEAK MSCGM (Lonza), as standard commercially available products. These are chemically pre-defined and contain recombinant, highly purified hormones and growth factors. In a 2014 study, culture of human WJ-
MSCs in MesenCult XF medium resulted in increased proliferation, higher number of colony-forming units, improved immunosuppression and higher angiogenic potency compared with standard KnockOut Dulbecco's Modified Eagle's Medium/10\% FBS medium [86]. Although these commercially available media are chemically pre-defined and superior to media containing FBS, variations in cellular properties are observed between manufacturers $[84,86]$. The authors recommend that a pilot study be performed in which several commercially available media are extensively compared using the same cell type, isolation technique, seeding density and passages in a single laboratory setup, if possible, to establish standard practices.

\section{Long-Term Culture and Cryopreservation}

Owing to the large number of cells required in a single dose and the low yield of MSCs from any tissue source at passage zero, long-term in vitro passaging/expansion of MSCs is inevitable. However, decreased proliferation and increased replicative senescence appearing in later passages are a point of concern. Widowati et al. [87] reported that with increasing passage number, proliferation capacity of AD-MSCs reduced, though morphology was unaffected. By contrast, Koltsova et al. [88] showed that WJ-MSCs displayed higher population doubling time and underwent replicative senescence by passage 13 , accompanied by morphological changes. A similar observation was reported by Zhuang et al. [89] in which UC-MSCs became senescent by passage 15 compared with passage three, though passage 13 MSCs showed higher immunomodulatory potential in vitro as a result of increased heme oxygenase 1 , IL-10, IL-6 and inducible nitric oxide synthase gene expression, with no significant change in the anti-inflammatory cytokine TGF- $\beta$. In addition, functional analysis of senescent BM-MSCs revealed that their immunoregulatory properties were diminished and they were ineffective in treating endotoxemia-induced septic mice. Moreover, in vitro migration toward lipopolysaccharide-stimulated macrophages was affected Sepulveda et al., 2014 [90]. Moghadam et al. [91]demonstrated significant reduction in messenger RNA (mRNA) expression of IL-10 at passage nine compared with passage seven AD-MSCs. Additionally, vascular cell adhesion protein 1 and IL-6 mRNA expression in BM-MSCs declined significantly by passage seven compared with passage three. Another study performed by de Witte et al. [92] reported that the capacity to inhibit T-cell proliferation in vitro declined with increasing passage numbers of both BM-MSCs and UC-MSCs. That being said, further investigation establishing superior functional efficacy of late passages of MSCs obtained from a particular tissue source compared with earlier passages of another source is essential in determining an optimal passage number.

Biodistribution studies have demonstrated impaired kinetics of intravenously transplanted MSCs, with the cells getting trapped in lung capillaries and then rapidly being cleared within $24 \mathrm{~h}$. This phenomenon, known as the first-pass effect, has been attributed to increases in cell size and phenotypic changes occurring over repeated passaging as well as the triggering of innate and adaptive immune cell responses, resulting in IBMIR [93]. Moll et al. [71] demonstrated a highly significant increase in TF expression in passage six versus passage three BM-MSCs, indicating a higher IBMIR-inducing capacity at higher passages. 
Considering this, the authors suggest finding a middle ground with respect to the extent of passaging/expansion. Use of cells from passages three to six will avoid loss of MSC proliferation ability and replicative senescence and preserve immunoregulatory efficacy while minimizing the risk of IBMIR due to TF activation. For this, a higher amount of starting material will of course be required, and the umbilical cord again appears to be the most appropriate choice.

Another variable in determining the quality of MSC preparations is the cryopreservation. To achieve bedside transplantation, a common practice is to thaw the vial containing a pre-determined dose, resuspend in an electrolyte solution and inject. Although this method is logistically convenient, allows rapid access and availability and eases the process of quality control [94,95], it can severely hamper viability if not done quickly by experienced handlers. Although the majority of the literature suggests minimal to no adverse effects of cryopreservation on MSC morphology, immunophenotype, proliferation and trilineage differentiation [95,96], very few studies have investigated immunomodulatory parameters. Moll et al. [97] demonstrated a significant increase in IBMIR after blood exposure of thawed early passage (two to four) MSCs compared with fresh cultures in addition to increased complement-mediated cell lysis. Also, fresh MSCs expressed significantly higher IDO mRNA upon stimulation for $24 \mathrm{~h}$ with IFN- $\gamma$ compared with freeze-thawed cells. However, IDO expression of freeze-thawed MSCs was restored after 7 days of IFN- $\gamma$ licensing, suggesting stabilization in immunosuppressive activity. Another review article extensively details the effect of freeze-thawing on the membrane physiology and metabolism of MSCs [93]. Freeze-thawing was reported to affect MSC membrane asymmetry, heat-shock protein expression and cytoskeletal aberrations, leading to cell shrinkage, cytoplasmic leakage and apoptotic body formation and resulting in an increased risk of host immune system recognition and, ultimately, attack on infused MSCs. Furthermore, freeze-thawed cells, when resuspended in single-cell suspensions, display hampered aggregation, antigen adsorption, microvascular toxicity and reduced hemocompatibility. By contrast, some studies have reported restoration of these cellular parameters and functional recovery shortly upon subculture. These data indicate that a restart period could help regain functionality of physiological processes. Further investigation using a cryorecovery approach is indicated.

Another significant concern is the cryopreservation used. As we move toward a serum/xeno-free approach, methods of eliminating the conventional 10\% dimethyl sulfoxide (DMSO)/90\% FBS cryopreservation medium are being developed. Also, the use of DMSO is a probable reason for impaired MSC membrane physiology and increased vulnerability to complement activation and IBMIR [93]. Grein et al. [98] reported a post-thaw viability of $72 \%$ in human MSC-telomerase reverse transcriptase cultures after cryopreservation with $10 \%$ Ectoin compared with $10 \%$ DMSO. In another attempt to avoid the use of DMSO, Shivakumar et al. [99] showed that freezing in a cocktail solution of advanced Dulbecco's Modified Eagle's Medium containing 10\% (v/v) FBS, $0.05 \mathrm{M}$ glucose, $0.05 \mathrm{M}$ sucrose and $1.5 \mathrm{M}$ ethylene glycol resulted in $72.2 \%$ post-thaw viability. Although these studies suggest alternatives for DMSO, they are limited to cell survival, phenotype and differentiation and do not extensively address effects on the immunomodulatory functions of MSCs. Also, serum-free cryopreservation media with reduced concentrations of DMSO, including CryoStor CS2 and CryoStor CS5 (Stem Cell Technologies) and STEM-CELLBANKER (Amsbio), are commercially available, though studies analyzing their effect on the phenotypic and functional properties of MSCs are required.

\section{Defining a Transplantation Window: The "When"}

Recently, concerns regarding potential lethal consequences of MSC transplantation into patients at risk of DIC have been voiced [16]. These concerns are due to the differential expression of TF/
CD142 among MSCs isolated from different sources and were first raised by Moll et al. [16], who recommended caution when infusing TF-rich MSCs in a hyper-coagulable state. Christy et al. [100] showed that although AD-MSCs and BM-MSCs both expressed TF/CD142, the expression varied drastically between donors and population doublings, indicating a pro-coagulant phenotype. Further, Oeller et al. [101] showed that intravenous injection of TF-deficient BM-MSCs did not produce thromboembolism in the lungs, liver or spleen of rats compared with the massive intravascular thrombosis observed in the TF-expressing BM-MSC group. Considering this variability in TF/ CD142 expression between sources and donors, the authors of the current study also suggest adding TF/CD142 to the standard phenotypic characterization panel of MSCs for elimination of samples with high CD142 expression as well as the use of anticoagulants like heparin during transplantation. Another approach to aid in decreasing complications associated with the use of intravenous "pro-coagulant" MSCs in the "hyper-coagulable" COVID-19 condition would be identifying a transplantation window by staging patients based on their pro-inflammatory profile, as outlined by Siddiqi and Mehra [1]. Early transplantation during the pulmonary phase, or stage II, during which there is moderate pulmonary involvement without hypoxia, accompanied by anticoagulants might provide the highest benefit and even slow disease progression. As inflammation is confined to the lungs at this stage, intravenously administered MSCs will get licensed and assert their regenerative effects locally. An alternative approach could be the use of the intramuscular route of injection, as it directly avoids the lung vasculature and potentiates MSC dwell time, as shown in previous studies [102,103]. Furthermore, in a previous report, the authors showed that dental pulp stem cells transplanted intramuscularly into physiologically healthy, immunocompetent rats migrate to the bone marrow in $24 \mathrm{~h}$ and also overcome the first-pass effect seen with the intravenous route, wherein the larger-sized MSCs are entrapped in lung capillaries, resulting in diminished efficacy [104].

\section{Identifying an Optimal Dosage: The "How Much"}

As mentioned earlier, the 60 clinical trials (Table 1 ) reviewed by the authors show extensive variability in their dosage regimens, defined as either "X" million cells/kg body weight or ballpark numbers like 25,100 or 300 million cells per dose (irrespective of body weight). To be able to easily compare these dosages, the authors calculated each dose (per injection) for an average body weight of $62 \mathrm{~kg}$. The most common dose was $1 \times 10^{6}$ cells $/ \mathrm{kg}$ body weight (i.e., $62 \times 10^{6}$ cells for a person weighing $62 \mathrm{~kg}$ ), which was used in $33.33 \%$ of registered trials. Only $8.33 \%$ of the studies employed a dose of $2 \times 10^{6}$ cells $/ \mathrm{kg}$ (i.e., $124 \times 10^{6}$ cells for a person weighing $62 \mathrm{~kg}$ ), whereas $10 \%$ used $0.5 \times 10^{6}$ cells $/ \mathrm{kg}$ (i.e., $31 \times 10^{6}$ cells for a person weighing $62 \mathrm{~kg}$ ) and $18.33 \%$ injected $100 \times 10^{6}$ cells irrespective of body weight. A total of $16.66 \%$ of these trials used doses below $100 \times 10^{6}$ cells (range, $20 \times 10^{6}$ cells to $99 \times 10^{6}$ cells). By contrast, $6.66 \%$ adopted higher numbers, ranging from $200 \times 10^{6}$ cells to $400 \times 10^{6}$ cells per dose. In addition to variations in the number of cells per dose, differences were observed in the frequency of injections (Figure 2B). Use of a single dose or three repeat doses was the most common, being performed by 16 studies each. Thirteen of the 60 studies chose two repeat doses, whereas five studies chose four repeat doses and two studies chose five repeat doses. Furthermore, the interval between repeat injections ranged from $24 \mathrm{~h}$ to 28 days (i.e., 672 h) (Table 1), with $48 \mathrm{~h}$ being the most common (14 of 60). Two studies specified $24 \mathrm{~h}$, eight studies specified $72 \mathrm{~h}$ and three studies specified 96 $\mathrm{h}$, whereas 13 of the 60 trials did not specify the interval.

Given that the scenario of COVID-19 pathophysiology has emerged only recently and is still evolving, it is no surprise that clinical data supporting the use of MSCs in treating the disease are limited. Thus far, only three studies for compassionate use of MSCs have been published $[62,63,105]$. Leng et al. [62] reported that a single 
intravenous dose of $1 \times 10^{6}$ cells/kg body weight with or without conventional anti-pyretic/anti-viral treatment was safe and efficient. All seven patients recovered or were discharged within 4-6 days of intervention. By contrast, Liang et al. [63] reported that three doses of $50 \times 10^{6}$ allogeneic UC-MSCs administered intravenously at intervals of 3 days were well tolerated in a 65-year-old critically ill COVID-19 patient, and recovery was observed owing to the immunomodulatory mechanisms of MSCs. Furthermore, Zhang et al. [105] transplanted $1 \times 10^{6}$ WJ-MSCs into a 54-year-old critically ill COVID-19 patient and reported recovery within 6 days as well as a negative test for COVID-19 nucleic acid. Even though these studies were performed on very small samples and were not powered for significance, a dose of $1 \times 10^{6}$ cells $/ \mathrm{kg}$ appears to be efficient. However, since a first-pass effect is seen in intravenously transplanted MSCs in which $>80 \%$ of the administered MSCs accumulate immediately in the lungs and are cleared with a half-life of $24 \mathrm{~h} \mathrm{[106],} \mathrm{the} \mathrm{use} \mathrm{of} \mathrm{very} \mathrm{high} \mathrm{doses} \mathrm{(up} \mathrm{to}$ 200 million) in current clinical trials is justified. Nonetheless, dose escalation studies performed in other diseases like type 2 diabetes, diabetic neuropathy and hip arthroplasty report that the use of cells in the mid-range (i.e., 100-150 million) leads to significant improvement in clinical symptoms compared with a very low dose (20 million) or very high dose (200-300 million) [107], suggesting that the use of higher numbers of cells does not equate to greater recovery. Moreover, higher and more severe incidents of immediate systemic adverse events were reported in phase $1 \mathrm{~b} / 2 \mathrm{a}$ clinical studies of multiple sclerosis and moderate to severe Crohn disease employing very high doses (4 units of $600 \times 10^{6}$ cells) of placenta-derived MSCs [72]. Also, serious infusion-related adverse effects, including pulmonary embolism, lung infarcts, elevated D-dimer levels and venous thrombosis, were seen in multiple studies transplanting $300 \times 10^{6}$ cells to $1200 \times 10^{6}$ cells, which correlated with the adverse effects seen with the use of perinatal-derived or AD-MSCs [72].

By contrast, repeated MSC administrations are consistently proving to be significantly more efficacious compared with a single dose. As mentioned earlier, given that approximately $80 \%$ of intravenously transplanted MSCs are cleared within $24 \mathrm{~h}$, repeat injections might overcome cell loss and maximize efficiency. Castro et al. [108] showed that three consecutive doses of $10^{5}$ AD-MSCs transplanted intravenously into an experimental house dust mite-induced allergic asthma mouse model reduced lung inflammation and reversed remodeling compared with one or two doses. In a previous study, the authors also showed that two doses of $1 \times 10^{6}$ dental pulp-derived MSCs administered intramuscularly into a rat model of diabetic neuropathy not only resulted in a significant reduction in systemic inflammation as well as improved nerve conduction velocity and reduced pain but also suggested that the second dose was essential for maintaining the improved state [109].

As far as the interval between repeated MSC administrations is concerned, the clearance rate of MSCs from the body can serve as a reference point for the next dose. However, this can only be determined using biodistribution studies. By now it is well established that intravenously transplanted MSCs first reach the lungs and then migrate to sites of inflammation. For example, Gholamrezanezhad et al. [110] showed that intravenously transplanted BM-MSCs in patients with advanced liver cirrhosis migrated to the liver and spleen by the 10th day post-infusion. As systemic inflammation and organ damage are observed in COVID-19 as well, the expectation is that transplanted MSCs will migrate to these sites and/or assert their regenerative effects via paracrine- or direct cell-cell-mediated mechanisms. Again, more definitive answers to this question can be obtained only through biodistribution experiments.

\section{Discussion}

The last few months have seen a rapid emergence of MSC therapy for COVID-19. Although investigators at academic institutions and eminent manufacturers like Mesoblast, Athersys, Pluristem and Cellavita are extensively involved in these studies, a scientific consensus with respect to quality, design, dosage and administration schedules for MSCs has yet to emerge. To minimize these inconsistencies, the authors propose that standardized protocols be established through a global consortium network. At the very least, existing regulatory bodies should consider coming together to establish a single unified protocol for fast-tracking the use of MSCs and making them available on a larger scale.

The authors also urge all MSC manufacturers to come forward and take the lead in making COVID-19 treatment widely available through their resources or existing MSC biobanks. A starting point for this would be a standardization of the production process and source protocols. In a recent review, Pittenger [111] rightly stated that "the MSC process is the MSC product," underlining the importance of process control in achieving consistent quality. In this review, the authors have emphasized not just the immunomodulatory and regenerative effects of WJ-MSCs but also their easy availability and potential for upscaling. Furthermore, the authors have discussed three other critical points of concern: (i) quality of MSCs (i.e., culture conditions); (ii) time of administration and dosage, the most important aspect of which is screening for TF/CD142 expression; and (iii) standard immunophenotyping, which needs to be integrated into the design of clinical trials.

\section{Conclusions}

The scientific community has conducted basic and clinical research on MSCs in many disease conditions for more than 20 years now and has already established their immunomodulatory and regenerative effects in COVID-19. Utilizing MSCs for COVID-19 will not only help in treating this disease but may also change the face of MSC therapy in other inflammatory and degenerative conditions.

\section{Funding}

The authors received funding from the Indian Council for Medical Research, Government of India (project no. 2019-2697/SCR/Adhoc/ BMS). PS is supported by a PhD fellowship from Lady Tata Memorial Trust, Mumbai, India.

\section{Declaration of Competing Interest}

The authors have no commercial, proprietary or financial interest in the products or companies described in this article.

\section{Acknowledgments}

The authors thank the vice chancellor and registrar of the National Institute of Mental Health and Neurosciences, Bengaluru, India, for providing their infrastructure facilities for the present work.

\section{References}

[1] Siddiqi HK, Mehra MR. COVID-19 illness in native and immunosuppressed states: a clinical-therapeutic staging proposal. The Journal of heart and lung transplantation : the official publication of the International Society for Heart Transplantation 2020;39(5):405-7.

[2] Symptoms of Coronavirus, Centers for Disease Control and Prevention, 2021 https://www.cdc.gov/coronavirus/2019-ncov/symptoms-testing/symptoms. html

[3] Kaye RJ. Overview of Stem Cell Therapy for Acute Respiratory Distress Syndrome with Focus on COVID 19. Pain physician 2020;23(4S). S421-S432.

[4] Mehta P, McAuley DF, Brown M, Sanchez E, Tattersall RS, Manson JJ, \& HLH Across Speciality Collaboration, UK (2020). COVID-19: consider cytokine storm syndromes and immunosuppression. Lancet (London, England), 395(10229), 1033-1034. https://doi.org/10.1016/S0140-6736(20)30628-0

[5] Manson JJ, Crooks C, Naja M, Ledlie A, Goulden B, Liddle T, Khan E, Mehta P, Martin-Gutierrez L, Waddington KE, Robinson GA, Ribeiro Santos L, McLoughlin E, 
Snell A, Adeney C, Schim van der Loeff I, Baker KF, Duncan C, Hanrath AT, Lendrem BC, ..., Tattersall RS. COVID-19-associated hyperinflammation and escalation of patient care: a retrospective longitudinal cohort study. The Lancet. Rheumatology 2020;2(10). e594-e602.

[6] Wiese OJ, Allwood BW, Zemlin AE. COVID-19 and the renin-angiotensin system (RAS): a spark that sets the forest alight? Medical hypotheses 2020;144:110231.

[7] Wauters E, Thevissen K, Wouters C, Bosisio FM, De Smet F, Gunst J, HumbletBaron S, Lambrechts D, Liston A, Matthys P, Neyts J, Proost P, Weynand B, Wauters J, Tejpar S, Garg AD. Establishing a Unified COVID-19 "Immunome". Integrating Coronavirus Pathogenesis and Host Immunopathology. Frontiers in immunology 2020;11:1642.

[8] Sinha P, Matthay MA, Calfee CS. Is a "Cytokine Storm" Relevant to COVID-19? JAMA internal medicine 2020;180(9):1152-4.

[9] Leisman DE, Ronner L, Pinotti R, Taylor MD, Sinha P, Calfee CS, Hirayama AV, Mastroiani F, Turtle CJ, Harhay MO, Legrand M, Deutschman CS. Cytokine elevation in severe and critical COVID-19: a rapid systematic review, meta-analysis, and comparison with other inflammatory syndromes. The Lancet. Respiratory medicine 2020;8(12):1233-44.

[10] Gustine JN, Jones D. Immunopathology of Hyperinflammation in COVID-19. The American journal of pathology 2021;191(1):4-17.

[11] Gupta A, Madhavan MV, Sehgal K, Nair N, Mahajan S, Sehrawat TS, Bikdeli B, Ahluwalia N, Ausiello JC, Wan EY, Freedberg DE, Kirtane AJ, Parikh SA, Maurer MS, Nordvig AS, Accili D, Bathon JM, Mohan S, Bauer KA, Leon MB, ..., Landry DW. Extrapulmonary manifestations of COVID-19. Nature medicine 2020;26 (7):1017-32

[12] Huertas A, Montani D, Savale L, Pichon J, Tu L, Parent F, Guignabert C, Humbert M. Endothelial cell dysfunction: a major player in SARS-CoV-2 infection (COVID19)? The European respiratory journal 2020;56(1). 2001634

[13] Gavriilaki E, Anyfanti P, Gavriilaki M, Lazaridis A, Douma S, Gkaliagkousi E. Endothelial Dysfunction in COVID-19: Lessons Learned from Coronaviruses. Current hypertension reports 2020;22(9):63.

[14] Evans PC, Rainger GE, Mason JC, Guzik TJ, Osto E, Stamataki Z, Neil D, Hoefer IE Fragiadaki M, Waltenberger J, Weber C, Bochaton-Piallat ML, Bäck M. Endothelial dysfunction in COVID-19: a position paper of the ESC Working Group for Atherosclerosis and Vascular Biology, and the ESC Council of Basic Cardiovascular Science. Cardiovascular research 2020;116(14):2177-84

[15] Connors JM, Levy JH. COVID-19 and its implications for thrombosis and anticoagulation. Blood 2020;135(23):2033-40.

[16] Moll G, Drzeniek N, Kamhieh-Milz J, Geissler S, Volk HD, Reinke P. MSC Therapies for COVID-19: Importance of Patient Coagulopathy, Thromboprophylaxis, Cell Product Quality and Mode of Delivery for Treatment Safety and Efficacy. Frontiers in immunology 2020;11:1091.

[17] Bordallo B, Bellas M, Cortez AF, Vieira M, Pinheiro M. Severe COVID-19: what have we learned with the immunopathogenesis? Advances in rheumatology 2020;60(1):50. (London, England).

[18] Signorini C, Pignatti P, Coccini T. How Do Inflammatory Mediators, Immune Response and Air Pollution Contribute to COVID-19 Disease Severity? A Lesson to Learn. Life (Basel, Switzerland) 2021;11(3):182.

[19] Triggle CR, Bansal D, Ding H, Islam MM, Farag E, Hadi HA, Sultan AA. A Comprehensive Review of Viral Characteristics, Transmission, Pathophysiology, Immune Response, and Management of SARS-CoV-2 and COVID-19 as a Basis for Controlling the Pandemic. Frontiers in immunology 2021;12:631139.

[20] Ellul MA, Benjamin L, Singh B, Lant S, Michael BD, Easton A, Kneen R, Defres S Sejvar J, Solomon T. Neurological associations of COVID-19. The Lancet. Neurology 2020;19(9):767-83.

[21] Mathew T, John SK, Sarma G, Nadig R, Kumar RS, Murgod U, Mahadevappa M, Javali M, Acharya PT, Hosurkar G, Krishnan P, Kamath V, Badachi S, Souza DD, Iyer RB, Nagarajaiah RK, Anand B, Kumar S, Kodapala S, Shivde S, ..., Huded V. COVID-19-related strokes are associated with increased mortality and morbidity: A multicenter comparative study from Bengaluru, South India. International journal of stroke : official journal of the International Stroke Society 2020:1747493020968236. Advance online publication. https://doi.org/10.1177| 1747493020968236.

[22] Cao W, Li T. COVID-19: towards understanding of pathogenesis. Cell research 2020;30(5):367-9.

[23] Ranucci M, Ballotta A, Di Dedda U, Bayshnikova E, Dei Poli M, Resta M, Falco M Albano G, Menicanti L. The procoagulant pattern of patients with COVID-19 acute respiratory distress syndrome. Journal of thrombosis and haemostasis: JTH 2020;18(7):1747-51.

[24] Cao X. COVID-19: immunopathology and its implications for therapy. Nature reviews. Immunology 2020;20(5):269-70.

[25] Paliogiannis P, Mangoni AA, Dettori P, Nasrallah GK, Pintus G, Zinellu A. D-Dimer Concentrations and COVID-19 Severity: A Systematic Review and Meta-Analysis. Frontiers in public health 2020;8:432.

[26] Zhao M. Cytokine storm and immunomodulatory therapy in COVID-19: Role of chloroquine and anti-IL-6 monoclonal antibodies. International journal of antimicrobial agents 2020;55(6):105982.

[27] Liu B, Li M, Zhou Z, Guan X, Xiang Y. Can we use interleukin-6 (IL-6) blockade for coronavirus disease 2019 (COVID-19)-induced cytokine release syndrome (CRS)? Journal of autoimmunity 2020;111:102452.

[28] Rahmati M, Moosavi M. Cytokine-targeted therapy in severely ill COVID-19 patients: Options and cautions. Eurasian journal of medicine and oncology 2020:4(2):179-81.

[29] Rider P, Carmi Y, Cohen I. Biologics for Targeting Inflammatory Cytokines, Clinical Uses, and Limitations. International journal of cell biology 2016;2016:9259646.
[30] Campochiaro C, Della-Torre E, Cavalli G, De Luca G, Ripa M, Boffini N, Tomelleri A, Baldissera E, Rovere-Querini P, Ruggeri A, Monti G, De Cobelli F, Zangrillo A, Tresoldi M, Castagna A, Dagna L. TOCI-RAF Study Group. Efficacy and safety of tocilizumab in severe COVID-19 patients: a single-centre retrospective cohort study. European journal of internal medicine 2020;76:43-9.

[31] Di Nicola M, Carlo-Stella C, Magni M, Milanesi M, Longoni PD, Matteucci P, Grisanti S, Gianni AM. Human bone marrow stromal cells suppress T-lymphocyte proliferation induced by cellular or nonspecific mitogenic stimuli. Blood 2002;99(10):3838-43.

[32] Glennie S, Soeiro I, Dyson PJ, Lam EW, Dazzi F. Bone marrow mesenchymal stem cells induce division arrest anergy of activated T cells. Blood 2005;105(7):2821-7.

[33] Niu J, Yue W, Le-Le Z, Bin L, Hu X. Mesenchymal stem cells inhibit T cell activation by releasing TGF- $\beta 1$ from TGF- $\beta 1 /$ GARP complex. Oncotarget 2017;8 (59):99784-800.

[34] Akiyama K, Chen C, Wang D, Xu X, Qu C, Yamaza T, Cai T, Chen W, Sun L, Shi S. Mesenchymal-stem-cell-induced immunoregulation involves FAS-ligand-/FASmediated T cell apoptosis. Cell stem cell 2012;10(5):544-55.

[35] Weiss A, Dahlke MH. Immunomodulation by Mesenchymal Stem Cells (MSCs): Mechanisms of Action of Living, Apoptotic, and Dead MSCs. Frontiers in immunology 2019;10:1191.

[36] Krampera M. Mesenchymal stromal cell 'licensing’: a multistep process. Leukemia 2011;25(9):1408-14

[37] Li N, Hua J. Interactions between mesenchymal stem cells and the immune system. Cellular and molecular life sciences: CMLS 2017;74(13):2345-60.

[38] Wang M, Yuan Q Xie L. Mesenchymal Stem Cell-Based Immunomodulation: Properties and Clinical Application. Stem cells international 2018;2018:3057624.

[39] Noronha NC, Mizukami A, Caliári-Oliveira C, Cominal JG, Rocha J, Covas DT, Swiech K, Malmegrim K. Priming approaches to improve the efficacy of mesenchymal stromal cell-based therapies. Stem cell research \& therapy 2019;10 (1): 131

[40] Fan XL, Zhang Y, Li X, Fu QL. Mechanisms underlying the protective effects of mesenchymal stem cell-based therapy. Cellular and molecular life sciences: CMLS 2020;77:2771-94.

[41] Ramasamy R, Fazekasova H, Lam EW, Soeiro I, Lombardi G, Dazzi F. Mesenchymal stem cells inhibit dendritic cell differentiation and function by preventing entry into the cell cycle. Transplantation 2007;83(1):71-6.

[42] Kyurkchiev D, Bochev I, Ivanova-Todorova E, Mourdjeva M, Oreshkova T, Belemezova K, Kyurkchiev S. Secretion of immunoregulatory cytokines by mesenchymal stem cells. World journal of stem cells 2014;6(5):552-70.

[43] Reinders ME, Hoogduijn MJ. NK Cells and MSCs: Possible Implications for MSC Therapy in Renal Transplantation. Journal of stem cell research \& therapy 2014;4(2):1000166.

[44] Cho DI, Kim MR, Jeong HY, Jeong HC, Jeong MH, Yoon SH, Kim YS, Ahn Y. Mesenchymal stem cells reciprocally regulate the M1/M2 balance in mouse bone marrow-derived macrophages. Experimental \& molecular medicine 2014;46 (1). e70.

[45] Vasandan AB, Jahnavi S, Shashank C, Prasad P, Kumar A, Prasanna SJ. Human Mesenchymal stem cells program macrophage plasticity by altering their metabolic status via a $\mathrm{PGE}_{2}$-dependent mechanism. Scientific reports 2016;6:38308.

[46] Lee JW, Fang X, Gupta N, Serikov V, Matthay MA. Allogeneic human mesenchymal stem cells for treatment of E. coli endotoxin-induced acute lung injury in the ex vivo perfused human lung. 16357-62.

[47] Yang Y, Hu S, Xu X, Li J, Liu A, Han J, Liu S, Liu L, Qiu H. The Vascular Endothelial Growth Factors-Expressing Character of Mesenchymal Stem Cells Plays a Positive Role in Treatment of Acute Lung Injury In Vivo. Mediators of inflammation 2016;2016:2347938

[48] Hu S, Li J, Xu X, Liu A, He H, Xu J, Chen Q, Liu S, Liu L, Qiu H, Yang Y. The hepatocyte growth factor-expressing character is required for mesenchymal stem cells to protect the lung injured by lipopolysaccharide in vivo. Stem cell research $\mathcal{E}$ therapy, 2016;7(1):66.

[49] Harrell CR, Sadikot R, Pascual J, Fellabaum C, Jankovic MG, Jovicic N, Djonov V, Arsenijevic N, Volarevic V. Mesenchymal Stem Cell-Based Therapy of Inflammatory Lung Diseases: Current Understanding and Future Perspectives. Stem cells international 2019;2019:4236973.

[50] Zheng Y, Cai W, Zhou S, Xu L, Jiang C. Protective effect of bone marrow derived mesenchymal stem cells in lipopolysaccharide-induced acute lung injury mediated by claudin-4 in a rat model. American journal of translational research 2016;8(9):3769-79.

[51] Chen J, Hu C, Chen L, Tang L, Zhu Y, Xu X, Chen L, Gao H, Lu X, Yu L, Dai X, Xiang C, Li L. Clinical study of mesenchymal stem cell treating acute respiratory distress syndrome induced by epidemic Influenza A (H7N9) infection, a hint for COVID-19 treatment. Engineering (Beijing) 2020;6(10):1153-61.

[52] Ge Q, Zhang H, Hou J, Wan L, Cheng W, Wang X, Dong D, Chen C, Xia J, Guo J Chen X, Wu X. VEGF secreted by mesenchymal stem cells mediates the differentiation of endothelial progenitor cells into endothelial cells via paracrine mechanisms. Molecular medicine reports 2018;17(1):1667-75.

[53] Liang X, Zhang L, Wang S, Han Q, Zhao RC. Exosomes secreted by mesenchymal stem cells promote endothelial cell angiogenesis by transferring miR-125a. Journal of cell science 2016;129(11):2182-9.

[54] Chen QH, Liu AR, Qiu HB, Yang Y. Interaction between mesenchymal stem cells and endothelial cells restores endothelial permeability via paracrine hepatocyte growth factor in vitro. Stem cell research \& therapy 2015;6(1):44.

[55] Premer C, Blum A, Bellio MA, Schulman IH, Hurwitz BE, Parker M, Dermarkarian CR, DiFede DL, Balkan W, Khan A, Hare JM. Allogeneic Mesenchymal Stem Cells Restore Endothelial Function in Heart Failure by Stimulating Endothelial Progenitor Cells. EBioMedicine 2015;2(5):467-75. 
[56] Qin H, Zhao A. Mesenchymal stem cell therapy for acute respiratory distress syndrome: from basic to clinics. Protein \& cell 2020;11(10):707-22.

[57] Rogers CJ, Harman RJ, Bunnell BA, Schreiber MA, Xiang C, Wang FS, Santidrian AF, Minev BR. Rationale for the clinical use of adipose-derived mesenchymal stem cells for COVID-19 patients. Journal of translational medicine 2020;18 (1):203.

[58] Brault C, Zerbib Y, Kontar L, Fouquet U, Carpentier M, Metzelard M, Soupison T, De Cagny B, Maizel J, Slama M. COVID-19- versus non-COVID-19-related Acute Respiratory Distress Syndrome: Differences and Similarities. American journal of respiratory and critical care medicine 2020;202(9):1301-4.

[59] Haudebourg AF, Perier F, Tuffet S, de Prost N, Razazi K, Mekontso Dessap A, Carteaux G. Respiratory Mechanics of COVID-19- versus Non-COVID-19-associated Acute Respiratory Distress Syndrome. American journal of respiratory and critical care medicine 2020;202(2):287-90.

[60] Lopes-Pacheco M, Silva PL, Cruz FF, Battaglini D, Robba C, Pelosi P, Morales MM, Caruso Neves C, Rocco P. Pathogenesis of Multiple Organ Injury in COVID-19 and Potential Therapeutic Strategies. Frontiers in physiology 2021;12:593223.

[61] Matthay MA, Calfee CS, Zhuo H, Thompson BT, Wilson JG, Levitt JE, Rogers AJ, Gotts JE, Wiener-Kronish JP, Bajwa EK, Donahoe MP, McVerry BJ, Ortiz LA, Exline M, Christman JW, Abbott J, Delucchi KL, Caballero L, McMillan M, McKenna DH, ., Liu KD. Treatment with allogeneic mesenchymal stromal cells for moderate to severe acute respiratory distress syndrome (START study): a randomised phase 2a safety trial. The Lancet. Respiratory medicine 2019;7(2):154-62.

[62] Leng Z, Zhu R, Hou W, Feng Y, Yang Y, Han Q, Shan G, Meng F, Du D, Wang S, Fan J, Wang W, Deng L, Shi H, Li H, Hu Z, Zhang F, Gao J, Liu H, Li X, ..., Zhao RC. Transplantation of ACE2 - Mesenchymal Stem Cells Improves the Outcome of Patients with COVID-19 Pneumonia. Aging and disease 2020;11(2):216-28.

[63] Liang B, Chen J, Li T, Wu H, Yang W, Li Y, Li J, Yu C, Nie F, Ma Z, Yang M, Xiao M, Nie P, Gao Y, Qian C, Hu M. Clinical remission of a critically ill COVID-19 patient treated by human umbilical cord mesenchymal stem cells: A case report. Medicine 2020;99(31):e21429.

[64] Dominici M, Le Blanc K, Mueller I, Slaper-Cortenbach I, Marini F, Krause D, Deans R, Keating A, Prockop Dj, Horwitz E. Minimal criteria for defining multipotent mesenchymal stromal cells. The International Society for Cellular Therapy position statement. Cytotherapy 2006;8(4):315-7.

[65] Yoo KH, Jang IK, Lee MW, Kim HE, Yang MS, Eom Y, Lee JE, Kim YJ, Yang SK, Jung HL, Sung KW, Kim CW, Koo HH. Comparison of immunomodulatory properties of mesenchymal stem cells derived from adult human tissues. Cellular immunology 2009;259(2):150-6.

[66] Mattar P, Bieback K. Comparing the Immunomodulatory Properties of Bone Marrow, Adipose Tissue, and Birth-Associated Tissue Mesenchymal Stromal Cells. Frontiers in immunology 2015;6:560

[67] Laroye C, Boufenzer A, Jolly L, Cunat L, Alauzet C, Merlin JL, Yguel C, Bensoussan D, Reppel L, Gibot S. Bone marrow vs Wharton's jelly mesenchymal stem cells in experimental sepsis: a comparative study. Stem cell research \& therapy 2019;10 (1):192.

[68] Wagner W, Horn P, Castoldi M, Diehlmann A, Bork S, Saffrich R, Benes V, Blake J, Pfister S, Eckstein V, Ho AD. Replicative senescence of mesenchymal stem cells: a continuous and organized process. PloS one 2008;3(5). e2213.

[69] Kalaszczynska I, Ferdyn K. Wharton's jelly derived mesenchymal stem cells: future of regenerative medicine? Recent findings and clinical significance. BioMed research international 2015;2015:430847.

[70] Chu AJ. Tissue factor, blood coagulation, and beyond: an overview. International journal of inflammation 2011;367284.2011.

[71] Moll G, Rasmusson-Duprez I, von Bahr L, Connolly-Andersen AM, Elgue G, Funke L, Hamad OA, Lönnies H, Magnusson PU, Sanchez J, Teramura Y, Nilsson-Ekdahl K, Ringdén O, Korsgren O, Nilsson B, Le Blanc K. Are therapeutic human mesenchymal stromal cells compatible with human blood? Stem cells (Dayton, Ohio) 2012;30(7):1565-74

[72] Moll G, Ankrum JA, Kamhieh-Milz J, Bieback K, Ringdén O, Volk HD, Geissler S, Reinke P. Intravascular Mesenchymal Stromal/Stem Cell Therapy Product Diversification: Time for New Clinical Guidelines. Trends in molecular medicine 2019;25(2):149-63.

[73] Caplan H, Olson SD, Kumar A, George M, Prabhakara KS, Wenzel P, Bedi S, Toledano-Furman NE, Triolo F, Kamhieh-Milz J, Moll G, Cox Jr CS. Mesenchymal Stromal Cell Therapeutic Delivery: Translational Challenges to Clinical Application. Frontiers in immunology 2019;10. 1645.

[74] Siegel G, Kluba T, Hermanutz-Klein U, Bieback K, Northoff H, Schäfer R. Phenotype, donor age and gender affect function of human bone marrow-derived mesenchymal stromal cells. BMC medicine 2013;11:146.

[75] Zaim M, Karaman S, Cetin G, Isik S. Donor age and long-term culture affect differentiation and proliferation of human bone marrow mesenchymal stem cells, Annals of hematology 2012;91(8):1175-86.

[76] van de Vyver M. Intrinsic Mesenchymal Stem Cell Dysfunction in Diabetes Mellitus: Implications for Autologous Cell Therapy. Stem cells and development 2017;26(14):1042-53.

[77] Kornicka K, Houston J, Marycz K. Dysfunction of Mesenchymal Stem Cells Isolated from Metabolic Syndrome and Type 2 Diabetic Patients as Result of Oxidative Stress and Autophagy may Limit Their Potential Therapeutic Use. Stem cell reviews and reports 2018;14(3):337-45.

[78] Lukomska B, Stanaszek L, Zuba-Surma E, Legosz P, Sarzynska S, Drela K. Challenges and Controversies in Human Mesenchymal Stem Cell Therapy. Stem cells international 2019;2019:9628536.

[79] Costa LA, Eiro N, Fraile M, Gonzalez LO, Saá J, Garcia-Portabella P, Vega B, Schneider J, Vizoso FJ. Functional heterogeneity of mesenchymal stem cells from natural niches to culture conditions: implications for further clinical uses. Cellular and molecular life sciences: CMLS 2021;78(2):447-67.

[80] Yoon JH, Roh EY, Shin S, Jung NH, Song EY, Chang JY, Kim BJ, Jeon HW. Comparison of explant-derived and enzymatic digestion-derived MSCs and the growth factors from Wharton's jelly. BioMed research international 2013:428726. 2013.

[81] Khasawneh RR, Al Sharie AH, Abu-El Rub E, Serhan AO, Obeidat HN. Addressing the impact of different fetal bovine serum percentages on mesenchymal stem cells biological performance. Molecular biology reports 2019;46(4):4437-41.

[82] Gstraunthaler G, Lindl T, van der Valk J. A plea to reduce or replace fetal bovine serum in cell culture media. Cytotechnology 2013;65(5):791-3.

[83] Karnieli O, Friedner OM, Allickson JG, Zhang N, Jung S, Fiorentini D, Abraham E Eaker SS, Yong TK, Chan A, Griffiths S, Wehn AK, Oh S, Karnieli O. A consensus introduction to serum replacements and serum-free media for cellular therapies. Cytotherapy 2017;19(2):155-69.

[84] Cimino M, Gonçalves RM, Barrias CC, Martins M. Xeno-Free Strategies for Safe Human Mesenchymal Stem/Stromal Cell Expansion: Supplements and Coatings. Stem cells international 2017;2017:6597815.

[85] Oikonomopoulos A, van Deen WK, Manansala AR, Lacey PN, Tomakili TA, Ziman A, Hommes DW. Optimization of human mesenchymal stem cell manufacturing: the effects of animal/xeno-free media. Scientific reports 2015;5:16570.

[86] Swamynathan P, Venugopal P, Kannan S, Thej C, Kolkundar U, Bhagwat S, Ta M, Majumdar AS, Balasubramanian S. Are serum-free and xeno-free culture conditions ideal for large scale clinical grade expansion of Wharton's jelly derived mesenchymal stem cells? A comparative study. Stem cell research \& therapy 2014;5(4):88

[87] Widowati W, Noverina R, Ayuningtyas W, Kurniawan D, Kusuma H, Arumwardana S, Artie DS, Sholihah IA, Handayani R, Laksmitawati DR, Rinendyaputri R, Rilianawati R, Faried A. Proliferation, Characterization and Differentiation Potency of Adipose Tissue-Derived Mesenchymal Stem Cells (AT-MSCs) Cultured in Fresh Frozen and non-Fresh Frozen Plasma. International journal of molecular and cellular medicine 2019;8(4):283-94.

[88] Koltsova AM, Krylova TA, Musorina AS, Zenin VV, Turilova VI, Yakovleva TK, Poljanskaya GG. The Dynamics of Cell Properties during Long-Term Cultivation of Two Lines of Mesenchymal Stem Cells Derived from Wharton's Jelly of Human Umbilical Cord. Cell Tiss. Biol. 2018;12:7-19.

[89] Zhuang Y, Li D, Fu J, Shi Q Lu Y, Ju X. Comparison of biological properties of umbilical cord-derived mesenchymal stem cells from early and late passages: immunomodulatory ability is enhanced in aged cells. Molecular medicine reports 2015;11(1):166-74.

[90] Sepúlveda JC, Tomé M, Fernández ME, Delgado M, Campisi J, Bernad A, González MA Cell senescence abrogates the therapeutic potential of human mesenchymal stem cells in the lethal endotoxemia model. Stem cells (Dayton, Ohio) 2014;32(7):1865-77.

[91] Moghadam M, Tokhanbigli S, Baghaei K, Farivar S, Asadzadeh Aghdaei H, Zal MR. Gene expression profile of immunoregulatory cytokines secreted from bone marrow and adipose derived human mesenchymal stem cells in early and late passages. Molecular biology reports 2020;47(3):1723-32.

[92] de Witte S, Lambert EE, Merino A, Strini T, Douben H, O'Flynn L, Elliman SJ, de Klein A, Newsome PN, Baan CC, Hoogduijn MJ. Aging of bone marrow- and umbilical cord-derived mesenchymal stromal cells during expansion. Cytotherapy 2017;19(7):798-807.

[93] Moll G, Geißler S, Catar R, Ignatowicz L, Hoogduijn MJ, Strunk D, Bieback K, Ringdén O. Cryopreserved or Fresh Mesenchymal Stromal Cells: Only a Matter of Taste or Key to Unleash the Full Clinical Potential of MSC Therapy? Advances in experimental medicine and biology 2016;951:77-98.

[94] Oja S, Kaartinen T, Ahti M, Korhonen M, Laitinen A, Nystedt J. The Utilization of Freezing Steps in Mesenchymal Stromal Cell (MSC) Manufacturing: Potential Impact on Quality and Cell Functionality Attributes. Frontiers in immunology 2019;10:1627.

[95] Bahsoun S, Coopman K, Akam EC. The impact of cryopreservation on bone marrow-derived mesenchymal stem cells: a systematic review. Journal of translational medicine 2019;17(1):397.

[96] Fu X, Xu B, Jiang J, Du X, Yu X, Yan Y, Li S, Inglis BM, Ma H, Wang H, Pei X, Si W. Effects of cryopreservation and long-term culture on biological characteristics and proteomic profiles of human umbilical cord-derived mesenchymal stem cells. Clinical proteomics 2020;17:15

[97] Moll G, Alm JJ, Davies LC, von Bahr L, Heldring N, Stenbeck-Funke L, Hamad OA Hinsch R, Ignatowicz L, Locke M, Lönnies H, Lambris JD, Teramura Y, NilssonEkdahl K, Nilsson B, Le Blanc K. Do cryopreserved mesenchymal stromal cells display impaired immunomodulatory and therapeutic properties? Stem cells (Dayton, Ohio) 2014;32(9):2430-42.

[98] Grein TA, Freimark D, Weber C, Hudel K, Wallrapp C, Czermak P. Alternatives to dimethylsulfoxide for serum-free cryopreservation of human mesenchymal stem cells. The International journal of artificial organs 2010;33(6):370-80.

[99] Shivakumar SB, Bharti D, Jang SJ, Hwang SC, Park JK, Shin JK, Byun JH, Park BW, Rho GJ. Cryopreservation of Human Wharton's Jelly-derived Mesenchymal Stem Cells Following Controlled Rate Freezing Protocol Using Different Cryoprotectants; A Comparative Study. International journal of stem cells 2015;8(2):155-69.

[100] Christy BA, Herzig MC, Montgomery RK, Delavan C, Bynum JA, Reddoch KM, Cap AP. Procoagulant activity of human mesenchymal stem cells. The journal of trauma and acute care surgery 2017;83(1 Suppl 1):S164-9.

[101] Oeller M, Laner-Plamberger S, Hochmann S, Ketterl N, Feichtner M, Brachtl G, Hochreiter A, Scharler C, Bieler L, Romanelli P, Couillard-Despres S, Russe E, Schallmoser K, Strunk D. Selection of Tissue Factor-Deficient Cell Transplants as a Novel Strategy for Improving Hemocompatibility of Human Bone Marrow Stromal Cells. Theranostics 2018;8(5):1421-34. 
[102] Braid LR, Wood CA, Wiese DM, Ford BN. Intramuscular administration potentiates extended dwell time of mesenchymal stromal cells compared to other routes. Cytotherapy 2018;20(2):232-44.

[103] Hamidian Jahromi S, Davies JE. Concise Review: Skeletal Muscle as a Delivery Route for Mesenchymal Stromal Cells. Stem cells translational medicine 2019;8(5):456-65.

[104] Shahani P, Kaushal A, Waghmare G, Datta I. Biodistribution of IntramuscularlyTransplanted Human Dental Pulp Stem Cells in Immunocompetent Healthy Rats through NIR Imaging. Cells, tissues, organs 2020;209(4-6):215-26.

[105] Zhang Y, Ding J, Ren S, Wang W, Yang Y, Li S, Meng M, Wu T, Liu D, Tian S, Tian H, Chen S, Zhou C. Intravenous infusion of human umbilical cord Wharton's jellyderived mesenchymal stem cells as a potential treatment for patients with COVID-19 pneumonia. Stem cell research \& therapy 2020;11(1):207.

[106] Parekkadan B, Milwid JM. Mesenchymal stem cells as therapeutics. Annua review of biomedical engineering 2010;12:87-117.

[107] Kabat M, Bobkov I, Kumar S, Grumet M. Trends in mesenchymal stem cell clinical trials 2004-2018: Is efficacy optimal in a narrow dose range? Stem cells translational medicine 2020;9(1):17-27.

[108] Castro LL, Kitoko JZ, Xisto DG, Olsen PC, Guedes H, Morales MM, Lopes-Pacheco M, Cruz FF, Rocco P. Multiple doses of adipose tissue-derived mesenchymal stromal cells induce immunosuppression in experimental asthma. Stem cells translational medicine 2020;9(2):250-60.

[109] Datta I, Bhadri N, Shahani P, Majumdar D, Sowmithra S, Razdan R, Bhonde R. Functional recovery upon human dental pulp stem cell transplantation in a diabetic neuropathy rat model. Cytotherapy 2017;19(10):1208-24.

[110] Gholamrezanezhad A, Mirpour S, Bagheri M, Mohamadnejad M, Alimoghaddam K, Abdolahzadeh L, Saghari M, Malekzadeh R. In vivo tracking of 111In-oxine labeled mesenchymal stem cells following infusion in patients with advanced cirrhosis. Nuclear medicine and biology 2011;38(7):961-7.

[111] Pittenger MF, Discher DE, Péault BM, Phinney DG, Hare JM, Caplan AI. Mesenchymal stem cell perspective: cell biology to clinical progress. NPJ Regenerative medicine 2019;4:22.

[112] Berebichez-Fridman R, Montero-Olvera PR. Sources and Clinical Applications of Mesenchymal Stem Cells: State-of-the-art review. Sultan Qaboos University medical journal 2018;18(3). e264-e277.

[113] Petrenko Y, Vackova I, Kekulova K, Chudickova M, Koci Z, Turnovcova K, Kupcova Skalnikova H, Vodicka P, Kubinova S. A Comparative Analysis of Multipotent Mesenchymal Stromal Cells derived from Different Sources, with a Focus on Neuroregenerative Potential. Scientific reports 2020;10(1):4290 